\title{
Dispelling the Myth of Passivated Codoping in $\mathrm{TiO}_{2}$
}

Benjamin A. D. Williamson, ${ }^{\dagger, \ddagger \odot}$ John Buckeridge, ${ }^{\dagger \neq}$ Nicholas P. Chadwick, ${ }^{\S}, \|$ Sanjayan Sathasivam, ${ }^{\S}$ Claire J. Carmalt, ${ }^{\S(1)}$ Ivan P. Parkin, ${ }^{\S}$ and David O. Scanlon ${ }^{*},+,, \perp^{(1)}$

${ }^{\dagger}$ Department of Chemistry, University College London, 20 Gordon Street, London WC1H 0AJ, U.K.

${ }^{\ddagger}$ Thomas Young Centre, University College London, Gower Street, London WC1E 6BT, U.K.

${ }^{\S}$ Materials Research Centre, Chemistry Department, University College London, London WC1H 0AJ, U.K.

"Bio Nano Consulting, 85 Tottenham Court Road, London W1T 4TQ, U.K.

${ }^{\perp}$ Diamond Light Source Ltd., Diamond House, Harwell Science and Innovation Campus, Didcot, Oxfordshire OX11 0DE, U.K.

\author{
Supporting Information
}

ABSTRACT: Modification of $\mathrm{TiO}_{2}$ to increase its visible light activity and promote higher performance photocatalytic ability has become a key research goal for materials scientists in the past 2 decades. One of the most popular approaches proposed this as "passivated codoping", whereby an equal number of donor and acceptor dopants are introduced into the lattice, producing a charge neutral system with a reduced band gap. Using the archetypal codoping pairs of $[\mathrm{Nb}+\mathrm{N}]$ - and $[\mathrm{Ta}+$ $\mathrm{N}$ ]-doped anatase, we demonstrate using hybrid density functional theory that passivated codoping is not achievable in $\mathrm{TiO}_{2}$. Our results indicate that the natural defect chemistry of the host system (in this case n-type anatase $\mathrm{TiO}_{2}$ ) is dominant, and so concentration parity of dopant types is not achievable under any thermodynamic growth conditions. The implications of passivated codoping for band gap manipulation in general are discussed.

\section{INTRODUCTION}

$\mathrm{TiO}_{2}$, is an earth abundant, chemically stable wide band gap semiconductor that is used in a broad range of applications. In particular, titanium dioxide is used as a photocatalyst for the degradation of dyes and pollutants, ${ }^{1,2}$ the antimicrobial destruction of Staphylococcus aureus and Escherichia $\operatorname{coli}^{3-6}$ as well as the splitting of water into $\mathrm{H}_{2(\mathrm{~g})}$ and $\mathrm{O}_{2(\mathrm{~g})}{ }^{7-9}$ to name a few. $\mathrm{TiO}_{2}$ is popular in industry due to the wide range of scalable synthesis techniques such as sol-gel and chemical vapor deposition (CVD) that can be used to produce it. ${ }^{10}$ The main drawback, however, is its large band gap (anatase $=3.2$ $\mathrm{eV}$ ) meaning that solely UV light is absorbed accounting for only $\sim 1-2 \%$ of the total solar irradiation that reaches the earth's surface. ${ }^{11}$ In addition to this constraint, efficient photocatalysis demands that the conduction band minimum (CBM) and valence band maximum (VBM) must straddle the redox potentials of the species to be reduced/oxidized (e.g., for water splitting $\sim 1.23 \mathrm{eV}$ ) with a suitable overpotential of $\sim 0.2-0.3 \mathrm{eV}$ thereby requiring a band gap of $1.7-2.2 \mathrm{eV}$ for suitable visible light photocatalysis. ${ }^{11}$ Although the CBM of $\mathrm{TiO}_{2}$ is energetically favorable for the reduction of protons, ${ }^{12}$ the VBM is very low in energy (due to the high ionization potentials (IP) typical of n-type wide band gap materials ${ }^{13,14}$ dominated by deep lying $\mathrm{O} 2 \mathrm{p}$ states) producing highly localized holes states. ${ }^{15}$ Within the scientific literature, efforts to increase the efficiency of photocatalysis in $\mathrm{TiO}_{2}$ via band gap reduction have focused on "raising" the VBM through acceptor doping. ${ }^{16-20}$

This is typically achieved through nonmetal doping, i.e., with $\mathrm{B}{ }^{18,21-23} \mathrm{C},{ }^{19,24-26} \mathrm{~N},{ }^{16,17,27,28}$ or $\mathrm{P}^{16,20,29}$ In particular, nitrogen has been the "go-to" dopant for enhanced photocatalysis in $\mathrm{TiO}_{2}$ since the work of Asahi et al. in 2001. ${ }^{16}$ The popularity of $\mathrm{N}$-doping in anatase is also due to the reproducibility of these results through a range of solutionprocessed and deposition-based techniques, such as solgel, ${ }^{30,31} \mathrm{CVD},{ }^{32-34}$ or sputtering. ${ }^{35-37}$ When doping anatase with nitrogen, it is assumed that the $\mathrm{N} 2 \mathrm{p}$ states hybridize with the top of the valence band, lowering the band gap and ionization potential. However, despite over a decade of research, the exact nitrogen species that forms within the anatase lattice is still scrutinized. The position of $\mathrm{N}$ has been suggested to be either substitutional $\left(\mathrm{N}_{\mathrm{O}}\right.$ or $\left.\mathrm{N}_{\mathrm{Ti}}\right)$, interstitial $\left(\mathrm{N}_{\mathrm{i}}\right)$, or part of a complex species with the lattice ions or unintentional dopants, such as $\mathrm{H}\left(\mathrm{NH}_{4}{ }^{-}\right) \cdot{ }^{38-43}$ Interestingly, although experimental thin films of anatase display a red shifting of the band gap when nitrogen doped, $\mathrm{N}$-doped rutile thin films display a blue shift. This has been proposed to be due to the denser crystal structure of rutile forming a wider $\mathrm{O}$

Received: January 20, 2019

Revised: $\quad$ March 15, 2019

Published: March 17, 2019 
$2 p$ valence band, and upon nitrogen doping a reduction in Coulombic repulsion is observed. ${ }^{42}$ In reality, however, the nitrogen states form highly localized hole states just above the VBM corroborated through theoretical studies on both substitutional and interstitial nitrogen species. ${ }^{38,40-43}$ Within the density functional theory (DFT) literature, multiple groups have managed to show that interstitial $\mathrm{N}$ displaces from the perfect interstitial site toward a lattice oxygen to form an $\mathrm{N}-\mathrm{O}$ dumbbell which has also been corroborated using electron paramagnetic resonance (EPR) measurements. ${ }^{43}$ Unfortunately, these localized $\mathrm{N}$ states are a source of electron-hole recombination especially at the high concentrations typically required for "band gap reduction". 44,45 Theoretical studies have also proposed the inducement of oxygen vacancies due to nitrogen incorporation providing intrinsic compensation typical of the high ionization potential of $\mathrm{TiO}_{2}$ polymorphs. $^{12,42}$

Reports of beneficial carbon doping also exist in the literature, albeit less explored than nitrogen-doped $\mathrm{TiO}_{2}$ in both experiment and theory. Carbon possesses small ionic radii $\left(\sim 0.15-0.16 \AA^{46}\right)$ and generally prefers to exist as a $4+$ cation $\left(\mathrm{CH}_{4}, \mathrm{CO}_{2}\right.$ etc. $)$ although it can also exist in the 4- oxidation state as in TiC. Experimental techniques, such as X-ray photoelectron spectroscopy, ${ }^{47,48}$ suggest substitutional carbon $\left(\mathrm{C}_{\mathrm{O}}\right)$ species or carbonate species $\left(\mathrm{CO}_{3}{ }^{2-}\right)$ adsorbed into the lattice. Two theory papers, in particular, one by Di Valentin et al. $^{48}$ (using the standard Perdew-Burke-Ernzerhof functional) and a more recent hybrid DFT paper (HSE06) by Zhang and co-workers ${ }^{49}$ elucidate the possible locations and downsides to carbon doping in anatase. Both Di Valentin et al. and Zhang and co-workers recognize the existence of carbon replacing Ti in the lattice $\left(\mathrm{C}_{\mathrm{Ti}}\right)$ as a dominant defect whereby it acts as an isovalent dopant neither adding or removing electrons but possibly reducing the band gap at higher doping concentrations. $^{48,49,50}$ Due to the typical coordinations of carbon, it was found that $\mathrm{C}_{\mathrm{Ti}}$ defects prefer a four-coordinate configuration adding strain to the system due to the sixcoordinate environment of $\mathrm{Ti}$ (where $\mathrm{Ti}$ can hybridize $3 \mathrm{~d}$ orbitals). Due to the small ionic radii, interstitial carbon possesses relatively low formation energies under both $\mathrm{Ti}$ poor/O-rich and Ti-rich/O-poor conditions where it acts as a donor. $\mathrm{C}_{\mathrm{O}}$ is only expected to form toward highly $\mathrm{O}$-poor regimes where it induces the formation of oxygen vacancies thereby compensation occurs as with nitrogen defects. The defects that are expected to give states in the band gap suitable for visible light excitation are the $C_{O}$ related species which do not form as readily as substitutional nitrogen species. ${ }^{49}$

Transition metals can also act as acceptor dopants in particular $\mathrm{Ni},{ }^{51-53} \mathrm{Fe},{ }^{54-57} \mathrm{Co},{ }^{58-60} \mathrm{Cr},{ }^{61-64}$ and $\mathrm{Cu},{ }^{65-68}$ for example. It has been proposed that transition metal dopants provide an additional service by acting as an electron (or hole) trap enhancing the efficiency. ${ }^{69-72}$ Whether this increases or decreases electron-hole separation is still in debate with certain metal cations increasing the recombination rate (i.e., chromium) and others decreasing (i.e., copper and iron). ${ }^{45,73}$ Beneficial effects are not just limited to acceptor doping as donors such as $\mathrm{Nb},{ }^{10,74} \mathrm{Ta},{ }^{75-77} \mathrm{Sb},{ }^{78,79}$ or $\mathrm{W}^{80,81}$ also displays an enhancement of the photoactivity of anatase despite no band gap reduction or states within the band gap. The enhanced effects could likely be due to the increased electron concentration and mobility realized through donor doping and thus an increase in reducing electrons or even an enhanced surface segregation as seen with $\mathrm{Sb}$ and $\mathrm{Ta} .^{82,83}$
To rectify the recombination issues encountered from doping with nonmetals, an approach to fully passivate the dopant states while retaining the reduced band gap was proposed by Wei and co-workers. ${ }^{44}$ Within this formalism, the additional incorporation of a donor to the anatase lattice should have the effect of annihilating the additional holes brought about by acceptor doping and is shown schematically in Figure 1. Thus, the beneficial band gap narrowing exhibited

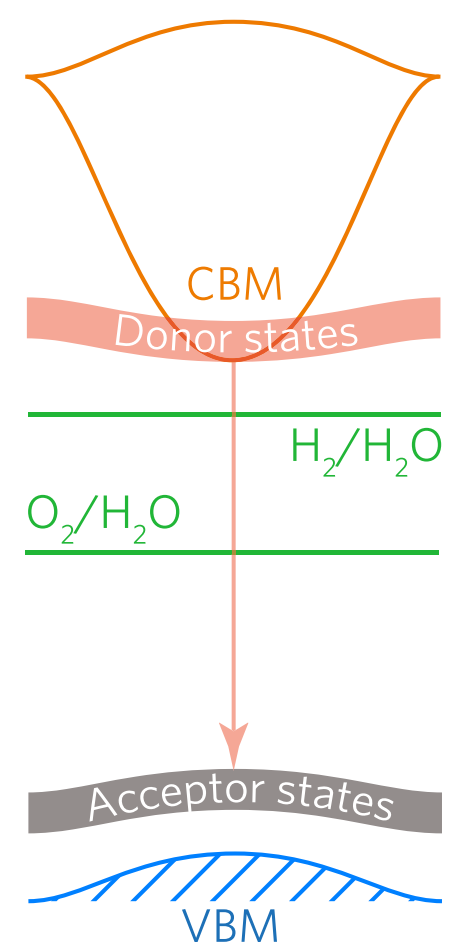

Figure 1. Schematic diagram for passivated codoping in $\mathrm{TiO}_{2}$ showing the positions of the band extrema relative to the redox potentials of water (green) and the acceptor (grey) and donor states (red).

by $\mathrm{N}$-doped $\mathrm{TiO}_{2}$ can be retained while alleviating the recombination centers. Due to the location of the anatase $\mathrm{CBM}$ relative to the reduction potential, ${ }^{12}$ a preferable resonant donor is required so that no downward shift of the CBM occurs. This makes $\mathrm{Nb}, \mathrm{Ta}, \mathrm{Mo}$, and $\mathrm{W}$ ideal donors for this effect. ${ }^{44,84}$ The original study by Gai et al. proposed four different codoped systems, $[\mathrm{V}+\mathrm{N}],[\mathrm{Nb}+\mathrm{N}],[\mathrm{Cr}+\mathrm{C}]$, and $[\mathrm{Mo}+\mathrm{C}]{ }^{44}$ Following from this study, the concept of "passivated codoping" became very popular, and each of the four proposed codoping pairs has been studied extensively experimentally $\left([\mathrm{Nb}+\mathrm{N}],{ }^{85-89}[\mathrm{Ta}+\mathrm{N}],^{90,91}[\mathrm{Cr}+\mathrm{C}],^{92}\right.$ $\left.[\mathrm{Mo}+\mathrm{C}]^{93-96}\right)$ with notable examples such as $[\mathrm{Nb}+\mathrm{N}]$ showing promising results such as the 7 -fold increase in photocatalytic degradation of methylene blue or the 4-fold increase in decomposition of methyl orange with $[\mathrm{Cr}+\mathrm{C}]$ codoped anatase. ${ }^{88,93}$ The term "full passivation" is used in this context to describe the concentration parity of acceptor and donor dopants.

Numerous computational studies have been carried out on codoped systems for band gap engineering, $44,84,97-109$ in particular a computational screening by Yan and co-workers found that $[\mathrm{Nb}+\mathrm{N}]$ and $[\mathrm{Ta}+\mathrm{N}]$ were ideal at a "high alloying concentration" regime, and that both $[\mathrm{Mo}+2 \mathrm{~N}]$ and $[\mathrm{W}+2 \mathrm{~N}]$ were ideal in a "low alloying concentration" regime. 
Carbon codoped systems were suggested to reduce the band gap too much, which combined with the problems associated with doping with $\mathrm{C}$ mean that reproducibility will be an issue in this context, despite a few promising results. ${ }^{93,95}$

Within the codoping literature, there exists a lack of distinction between the increased photoactivity seen due to passivated codoping and that seen from individually doping with either nonmetal or metal aliovalent ions. Claims are also made about the increase in photocatalytic activity such as with the 7-fold increase and 4-fold increase of $[\mathrm{Nb}+\mathrm{N}]$ and $[\mathrm{Mo}+$ C] systems of which the degradations of methylene blue and methyl orange rely just as much on reduction processes favouring an increased mobility and concentration of conduction band electrons. ${ }^{88,93}$ Methylene blue and methyl orange photocatalytic tests also rely on multistage degradation which can proceed via adsorption, therefore, making the difference between photocatalytic electron/hole transfer indistinguishable from other processes. Bartlett also remarked that stoichiometric pairing or full passivation of $\mathrm{Nb}+\mathrm{N}$ was not achieved, even providing a follow up study on the composition dependence of $\mathrm{Nb}$ and $\mathrm{N}$. $^{89}$ This work concluded that in fact a larger incorporation of $\mathrm{Nb}$ both decreased the optical band gap and increased the photoactivity and is echoed by Chadwick et al. ${ }^{86,89}$ Zhang et al. also noted that although $[\mathrm{Mo}+\mathrm{C}]$ showed an increase in the rate of methylene blue degradation compared to the undoped and carbon-doped $\mathrm{TiO}_{2}$ systems, they also found that $\mathrm{C}$ incorporates preferentially on the $\mathrm{Ti}$ site and thus cannot be deemed to provide full passivation. ${ }^{95}$ An analysis of the ionic radii of dopants in $\mathrm{TiO}_{2}$ shows that for $\mathrm{Nb}, \mathrm{Ta}, \mathrm{W}, \mathrm{Cr}, \mathrm{Mo}$, and $\mathrm{W}$, a range of $0.59-$ $0.64 \AA$ is observed (compared to $0.60 \AA$, for $\mathrm{Ti}$ ) making these highly soluble dopants, therefore low formation energies would be expected. $^{46}$

In this work, we demonstrate through theoretical calculations of the $[\mathrm{Nb}+\mathrm{N}]$ and $[\mathrm{Ta}+\mathrm{N}]$ codoped systems that charge compensation is simply not possible in anatase $\mathrm{TiO}_{2}$ under thermodynamic equilibrium due to its inherent n-type nature.

\section{COMPUTATIONAL METHODOLOGY}

Density functional theory (DFT) calculations using the periodic code, VASP (Vienna Ab-initio Simulation Package) ${ }^{110-113}$ and the hybrid HSE06 (Heyd-Scuseria-Ernzerhof) ${ }^{114}$ functional were performed on the bulk geometric and electronic relaxations as well as all studied intrinsic and extrinsic defects of anatase $\mathrm{TiO}_{2}$. The intrinsic defects and dopants $(\mathrm{Ta}, \mathrm{Nb}, \mathrm{N})$ were simulated using $3 \times 3 \times 2$ supercell expansions $(\sim 108$ atoms $)$ of the geometrically relaxed conventional cell of anatase $\mathrm{TiO}_{2}$. The HSE06 hybrid functional $^{115,116}$ provides excellent descriptions of the electronic and structural properties of all of the known polymorphs of $\mathrm{TiO}_{2},{ }^{10,12,117-123}$ and hybrid functionals are, in general, a marked improvement on local or semilocal DFT functionals as they better deal with the self-interaction error. ${ }^{124}$ The projector augmented wave ${ }^{125}$ method was utilized to describe the interactions between the core ( $\mathrm{Ti}[\mathrm{Ar}], \mathrm{O}[\mathrm{He}]$, $\mathrm{Ta}[\mathrm{Xe}], \mathrm{Nb}[\mathrm{Kr}], \mathrm{N}[\mathrm{He}])$ and valence electrons.

An initial geometry optimization of the bulk conventional cell was carried out minimizing the volume, lattice parameters, cell angles, and the ions within the cell until the forces acting on all of the atoms were less than $10 \mathrm{meV}^{-1}$. A $700 \mathrm{eV}$ planewave energy cutoff and a $\Gamma$-centered $7 \times 7 \times 5 k$-point mesh were sufficient to calculate the electronic and structural properties. The bulk electronic properties can be found in ref 123 . From this, a $3 \times 3 \times 2$ supercell containing 108 atoms was formed to evaluate the defect properties of the material. Geometry optimizations of each defective supercell and its respective charge states involved calculating the relaxation of only the ions within the cell, keeping the cell volume, lattice parameters, and angles fixed. A plane wave energy cutoff of 450 $\mathrm{eV}, \Gamma$-centered $2 \times 2 \times 2 k$-point mesh, and spin polarization were used to relax the supercells to the same force convergence as for the conventional bulk. The anatase lattice and dopant states are restricted by the formation of limiting phases (as discussed in the Supporting Information, SI) and are tabulated in Table 1 . Table 1 also displays the $k$-point meshes used in the

Table 1. Tabulated Chemical Potential Limits as Calculated with the HSE06 Hybrid Functional Together with Their Associated Spacegroup Symmetry and Structural Relaxation Parameters $^{a, b}$

\begin{tabular}{llcl} 
limit & spacegroup & $k$-point mesh & \multicolumn{1}{c}{$\Delta \mathrm{H}_{\mathrm{f}}(\mathrm{eV})$} \\
$\mathrm{TiN}$ & $\mathrm{F} m \overline{3} m$ & $8 \times 8 \times 8$ & $-3.49(-3.50)$ \\
$\mathrm{Ti}_{2} \mathrm{~N}$ & $P 42 / m n m$ & $5 \times 5 \times 8$ & $-4.07(\mathrm{~N} / \mathrm{A})$ \\
$\mathrm{NO}_{2}$ & $R \overline{3}$ & $4 \times 4 \times 4$ & $-0.26(\mathrm{~N} / \mathrm{A})$ \\
$\mathrm{N}_{2} \mathrm{O}_{5}$ & $C m$ & $5 \times 5 \times 4$ & $-0.13(\mathrm{~N} / \mathrm{A})$ \\
$\mathrm{Nb}_{2} \mathrm{O}_{5}$ & $I 4 / m m m$ & $2 \times 2 \times 2$ & $-18.48(-19.69)$ \\
$\mathrm{NbO}_{2}$ & $C 2 / c$ & $3 \times 3 \times 3$ & $-7.64(-8.24)$ \\
$\mathrm{NbO}$ & $P m 3 m$ & $6 \times 6 \times 6$ & $-4.10(-4.35)$ \\
$\mathrm{Ta}_{2} \mathrm{O}_{5}$ & $I 41 /$ amd & $6 \times 6 \times 1$ & $-20.31(-21.21)$
\end{tabular}

${ }^{a}$ All $k$-point meshes are $\Gamma$-centered. ${ }^{b}$ The calculated enthalpies of formation $\Delta H_{\mathrm{f}}$ for the relaxed structures are also tabulated with experimental values ${ }^{126}$ in parentheses.

geometry optimizations (force convergence criterion: $<10 \mathrm{meV}$ $\left.\AA^{-1}\right)$ and the calculated enthalpies of formation $\left(\Delta H_{\mathrm{f}}\right)$. These enthalpies of formation are in good agreement with the standard temperature and pressure experimental results, with differences expected due to the difference in temperature (DFT formation energies are calculated at $0 \mathrm{~K}$ ) and may be due to the choice of the HSE06 functional for these limits.

Defect Formalism. Equation 1 defines the enthalpy of formation for a defect $(D)$ in charge state, $q$.

$$
\begin{aligned}
\Delta H_{\mathrm{f}}(D, q)= & \left(E^{D, q}-E^{\mathrm{H}}\right)+\sum_{i} n_{i}\left(E_{i}+\mu_{i}\right) \\
& +q\left(E_{\mathrm{F}}+\epsilon_{\mathrm{VBM}}^{\mathrm{H}}+\Delta E_{\mathrm{POT}}\right)+E_{\mathrm{CORR}}[q]
\end{aligned}
$$

Where

$$
E_{\mathrm{CORR}}[q]=q^{2} E_{\mathrm{CORR}}^{\mathrm{IC}}+E_{\mathrm{CORR}}^{\mathrm{BF}}
$$

$E^{D, q}$ is the total energy of the defective supercell in charge state $q$ and $E^{\mathrm{H}}$ is the total energy of the host supercell. $E_{i}$ and $\mu_{i}$ refer to the elemental reference energy and chemical potentials of species " $i$ " $\left(\mathrm{Ti}_{(\mathrm{s})}, \mathrm{O}_{(\mathrm{g})}, \mathrm{Ta}_{(\mathrm{s})}, \mathrm{Nb}_{(\mathrm{s})}\right.$, and $\left.\mathrm{N}_{(\mathrm{g})}\right)$, respectively. $n_{i}$ is either negative or positive depending on whether the species is added to or removed from the system. The Fermi energy $\left(E_{\mathrm{F}}\right)$ ranges from the valence band maximum (VBM) to the conduction band minimum (CBM). The band gap $\left(E_{\mathrm{g}}\right)$ of anatase has been determined to be $3.41 \mathrm{eV}$ from our primitive cell calculations consistent with other ab initio works. ${ }^{2,127-132}$ $\epsilon_{\mathrm{VBM}}^{\mathrm{H}}$ refers to the eigenvalue of the VBM from the host supercell calculation, and $\Delta E_{\mathrm{POT}}$ is a potential alignment term to account between the difference between electrostatic 
potentials between the defective and host supercells. To account for the finite size of the supercell, two corrections are applied; $E_{\mathrm{CORR}}^{\mathrm{IC}}$ and $E_{\mathrm{CORR}}^{\mathrm{BF}}$. The former correction is an imagecharge correction which is necessary due to the long-ranged nature of the Coulomb interaction, ${ }^{133,134}$ thus correcting for the interaction of the defect with its periodic images. The scheme used herein utilizes the formalism by Hine and Murphy ${ }^{135}$ based on the Lany and Zunger correction. ${ }^{136}$ The latter correction, $E_{\mathrm{CORR}}^{\mathrm{BF}}$, corresponds to a band filling correction $^{136,137}$ associated with the relatively high defect concentrations that give rise to an unphysical band gap renormalization present for the finite-sized supercell calculation.

Thermodynamic Limits. To determine the enthalpies of formation for a given defect over a chemical potential range relating to the equilibrium growth conditions of the host material $\left(\mathrm{TiO}_{2}\right)$, competing phases must be calculated to create upper and lower bounds on the phase space.

The chemical potential bounds placed on the host can be calculated through the enthalpies of the formation of anatase $\mathrm{TiO}_{2}$

$$
\mu_{\mathrm{Ti}}+2 \mu_{\mathrm{O}}=\Delta H_{\mathrm{f}}^{\mathrm{TiO}_{2}}=-9.14 \mathrm{eV}
$$

Typically, the O-poor limit is determined by the formation of a secondary phase, $\mathrm{Ti}_{2} \mathrm{O}_{3}$, however, in practice, this is difficult to reach under general deposition temperatures and oxygen partial pressures in experiment. The $\mathrm{O}$-poor limit is thus rationalized to be in the region of $\mu_{\mathrm{O}}=-2 \mathrm{eV},{ }^{138,139}$ which is what we will use as our Ti-rich/O-poor limit in this study. The Ti-poor/O-rich boundary is limited via the formation of oxygen gas $\left(\mathrm{O}_{2(\mathrm{~g})}\right)$; thus, the chemical potential ranges for $\mathrm{Ti}$ and $\mathrm{O}$ are

$$
\text { Ti-poor/O-rich: } \mu_{\mathrm{O}}=0 \mathrm{eV} ; \mu_{\mathrm{Ti}}=-9.14 \mathrm{eV}
$$

and

$$
\text { Ti-rich/O-poor: } \mu_{\mathrm{O}}=-2 \mathrm{eV} ; \mu_{\mathrm{Ti}}=-5.14 \mathrm{eV}
$$

The limiting phases for $\mathrm{Nb}$ and $\mathrm{N}$ are shown in SI Figure 1 and demonstrate that under the chemical potential range, $\mathrm{Nb}_{2} \mathrm{O}_{5}$ is the limiting phase for $\mu_{\mathrm{Nb}}$ and that under Ti-rich/O-poor and Ti-poor/O-rich conditions, $\mathrm{N}_{2(\mathrm{~g})}$ and $\mathrm{NO}_{2}$ are the limiting phases, respectively. For $\mu_{\mathrm{Ta}}$ the limiting phase is $\mathrm{Ta}_{2} \mathrm{O}_{5}$. Further limits are placed upon the dopant species added to the system. The dopant chemical potentials are thus: Ti-poor/Orich

$$
\mu_{\mathrm{N}}=-0.26 \mathrm{eV} ; \mu_{\mathrm{Nb}}=-9.24 \mathrm{eV} ; \mu_{\mathrm{Ta}}=-10.16 \mathrm{eV}
$$

Ti-rich/O-poor

$$
\mu_{\mathrm{N}}=-1.38 \mathrm{eV} ; \mu_{\mathrm{Nb}}=-0.62 \mathrm{eV} ; \mu_{\mathrm{Ta}}=-1.38 \mathrm{eV}
$$

The thermodynamic transition levels (Figure 2) display the thermal equilibrium transition from charge state $q$ to $q^{\prime}$ at a specific Fermi level and can be calculated using the equation

$$
\epsilon\left(q / q^{\prime}\right)=\frac{\Delta H_{\mathrm{f}}(D, q)-\Delta H_{\mathrm{f}}\left(D, q^{\prime}\right)}{q^{\prime}-q}
$$

Such transitions may be seen using experimental techniques such as deep level transient spectroscopy. ${ }^{140}$

Equilibrium Concentrations. The equilibrium defect and carrier concentrations were determined through calculation of the self-consistent Fermi energy, as implemented in the code
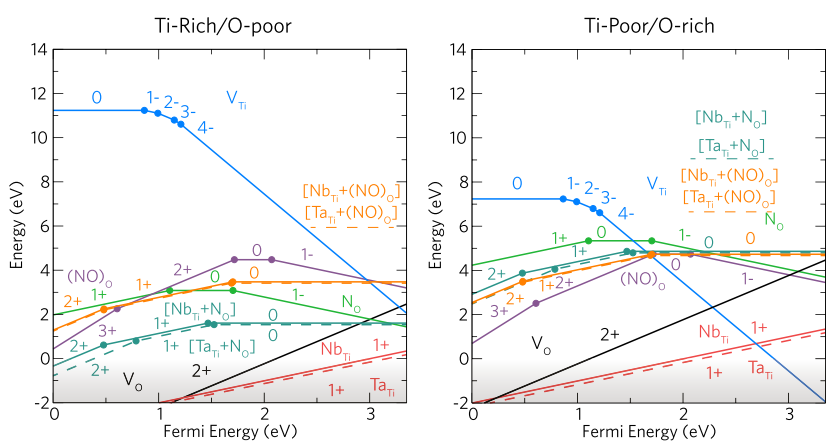

Figure 2. Calculated thermodynamic transition levels for both $\mathrm{Nb}$, $\mathrm{Ta}$, and $\mathrm{N}$-doped $\mathrm{TiO}_{2}$ under Ti-rich/O-poor growth conditions and under the Ti-poor/O-rich limit growth conditions. The Fermi energy ranges from the VBM to the CBM $(\sim 3.41 \mathrm{eV})$.

SC-FERMI. ${ }^{141,142}$ The concentration of defect $D$ in charge state $q,[D, q]$ is given by

$$
[D, q]=N_{D} g_{D, q} \exp (-\Delta H(D, q) / k T)
$$

where $N_{D}$ is the density of sites on which the defect in question can form, $g_{D, q}$ is the degeneracy of the defect state, $k$ is Boltzmann's constant, and $T$ is the temperature. Electron $\left(n_{0}\right)$ and hole $\left(p_{0}\right)$ concentrations are determined using the equations

$$
\begin{aligned}
& n_{0}=\int_{E_{\mathrm{g}}}^{\infty} f_{\mathrm{e}}(E) \rho(E) \mathrm{d} E \\
& p_{0}=\int_{-\infty}^{0} f_{\mathrm{h}}(E) \rho(E) \mathrm{d} E
\end{aligned}
$$

where $\rho(E)$ is the density of states (DOS), $E_{\mathrm{g}}$ is the band gap, $f_{\mathrm{e}}(E)=\left[\exp \left(\left(E_{\mathrm{F}}-E\right) / k T\right)+1\right]^{-1}$ is the Fermi-Dirac distribution function, and $f_{\mathrm{h}}(E)=1-f_{\mathrm{e}}(E)$ (the energy scale is defined so that the VBM is zero). The defect and carrier concentrations are functions of $E_{\mathrm{F}}$ via $\Delta H(D, q), f_{\mathrm{e}}(E)$, or $f_{\mathrm{h}}(E)$; given the constraint of overall charge neutrality, it is therefore possible to determine the self-consistent value of $E_{\mathrm{F}}$ and hence the equilibrium concentrations at $T$.

\section{RESULTS}

Defect Thermodynamics. To understand the thermodynamic defect chemistry of codoped anatase $\mathrm{TiO}_{2}$, density functional theory using the hybrid functional, HSE06 ${ }^{114}$ was utilized. HSE06 has previously been shown to accurately reproduce the electronic and geometric structures of $\mathrm{TiO}_{2}$ polymorphs relative to experiment. ${ }^{10,12,118-123} \mathrm{An}$ analysis of the density of states (DOS), geometry, and band structure of anatase $\mathrm{TiO}_{2}$ has been carried out previously in ref 123 . The thermodynamic transition level diagrams for the intrinsic and extrinsic defects are shown in Figure 2. These are depicted under two different growth regimes, an experimentally viable Ti-rich/O-poor and an Ti-poor/O-rich limit.

Intrinsic Defects. The dominant acceptor $\left(\mathrm{V}_{\mathrm{Ti}}\right)$ and donor $\left(\mathrm{V}_{\mathrm{O}}\right)$ defect species were calculated within the anatase lattice. ${ }^{18,143-147}$ Under the n-type "favorable" conditions of Ti-rich/O-poor conditions, $\mathrm{V}_{\mathrm{O}}$ is the lowest formation energy intrinsic defect $\left(\Delta H_{\mathrm{f}}\left(\mathrm{V}_{\mathrm{O}}\right)=\sim 2.71 \mathrm{eV}\right)$, and under Ti-poor/Orich growth conditions ( $\mathrm{p}$-type favorable), this raises to $\sim 4.71$ eV. In $\mathrm{TiO}_{2}, \mathrm{~V}_{\mathrm{O}}$ is a resonant two-electron donor where the $2+/ 0$ transition level exists $\sim 0.12 \mathrm{eV}$ above the CBM $(\sim 3.41$ $\mathrm{eV})$. This is in contrast to $\mathrm{SnO}_{2}, \mathrm{ZnO}$, and $\mathrm{BaSnO}_{3}$ where the 


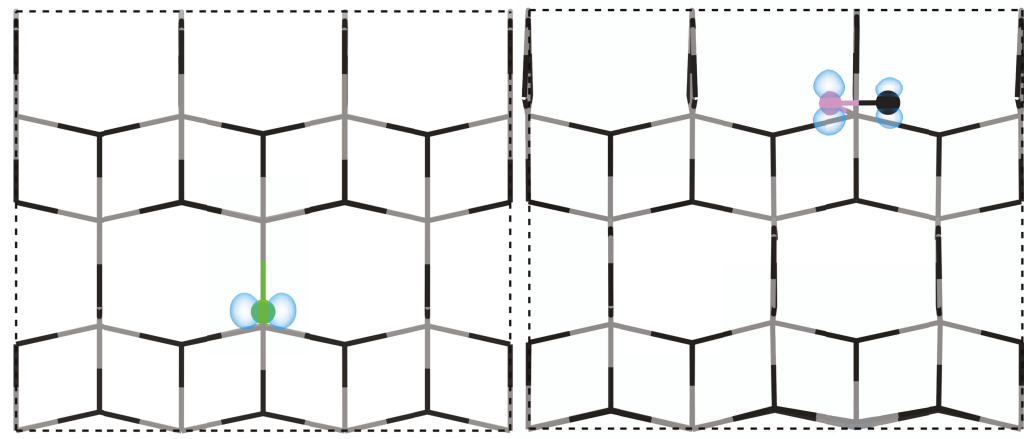

(a) (b)

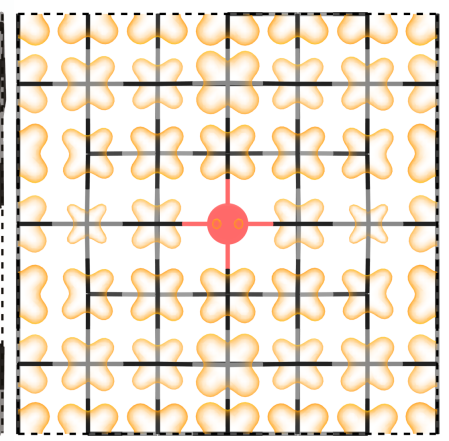

(c)

Figure 3. Partial charge densities of $(\mathrm{a}) \mathrm{N}_{\mathrm{O}}^{0}$ and (b) $(\mathrm{NO})_{\mathrm{O}}^{0}$ as viewed along the [100] direction and $(\mathrm{c}) \mathrm{Nb}(\mathrm{Ta})_{\mathrm{Ti}}^{0}$ as viewed along the [001] direction. The anatase lattice $(\mathrm{Ti}=$ gray, $\mathrm{O}=$ black $)$ is depicted by the wire-frame lattice, and the nitrogen and $\mathrm{Nb}(\mathrm{Ta})$ species, by the colored orbs (color coded to Figure 2). The charge isosurfaces for holes are shown in blue and plotted from 0 to $0.02 \mathrm{eV}^{-1}$ and the electron charge density in orange and plotted from 0 to $0.002 \mathrm{eV} \AA^{-1}$.

$2+/ 0$ transition level is in the band gap acting as a deep donor and is not expected to contribute to the electronic conductivity of these materials. ${ }^{14,148-155}$

The titanium vacancy $\left(\mathrm{V}_{\mathrm{Ti}}\right)$, under Ti-poor/O-rich conditions where its formation is most conducive still has a large formation energy in the neutral charge state of $\sim 7.23 \mathrm{eV}$. This value rises to $\sim 11.24 \mathrm{eV}$ under Ti-rich/O-poor conditions. Under both sets of conditions, the $0 / 1-$ transition level occurs $\sim 0.87 \mathrm{eV}$ above the $\mathrm{VBM}$, making $\mathrm{V}_{\mathrm{Ti}}$ a very deep acceptor. Under O-rich conditions, $\mathrm{V}_{\mathrm{Ti}}^{4-}$ begins to compensate $\mathrm{V}_{\mathrm{O}}^{2+} \sim 2.28$ $\mathrm{eV}$ above the VBM trapping the Fermi level around this point. The position of compensation by $\mathrm{V}_{\mathrm{Ti}}^{4-}$ under Ti-rich/O-poor conditions occurs $\sim 0.06 \mathrm{eV}$ below the CBM.

To assess the ability of fully passivated codoping in $\mathrm{TiO}_{2}$, the defect thermodynamics of the $\mathrm{TiO}_{2}:[\mathrm{Nb}+\mathrm{N}]$ and $\mathrm{TiO}_{2}$ : $[\mathrm{Ta}+\mathrm{N}]$ systems were analyzed and compared. These systems were chosen due to their abundance in the literature and from previous theory calculations identifying them as ideal candidates for water splitting. ${ }^{44,84-91,100,156,157}$ Both $\mathrm{Nb}$ and $\mathrm{Ta}$ have been shown to easily dope into $\mathrm{TiO}_{2}{ }^{10,74-77,158}$ and success has been seen in $\mathrm{N}$-doped $\mathrm{TiO}_{2} \cdot{ }^{16,17,27,28}$ The calculations of these defects were carried out alongside the possible codoped clusters in $\mathrm{TiO}_{2}$ using the hybrid HSE06 $^{115,116}$ functional.

Mono Doping of Anatase with $\mathrm{N}, \mathrm{Nb}$, and Ta. All mono-doped anatase $\mathrm{TiO}_{2}$ systems were analyzed to determine the thermodynamic viability of the chosen defects and any points of unintentional compensation. Figure 2 displays the transition levels for the $\mathrm{N}-, \mathrm{Nb}-$, and Ta-related defects in anatase.

Nitrogen Doping. Within the anatase lattice, $\mathrm{N}$ can exist both substitutionally and interstitially. Substitutional nitrogen, $\mathrm{N}_{\mathrm{O}}$, acts as an amphoteric defect under both growth regimes with a relatively high formation energy (neutral charge state) of 3.08 and $5.34 \mathrm{eV}$ under Ti-rich/O-poor and Ti-poor/O-rich conditions, respectively. Although O-rich conditions typically favor the formation of acceptor defects, $\mathrm{N}_{\mathrm{O}}$ is the highest in the formation energy under this growth regime. This is due to the higher $\mu_{\mathrm{O}}$ and thus lack of available oxygen sites reflected in the higher formation energy of $\mathrm{V}_{\mathrm{O}} \cdot \mathrm{N}_{\mathrm{O}}$ is both an ultradeep acceptor (0/1- transition $\sim 1.70 \mathrm{eV}$ above the VBM) and donor defect $(1+/ 0$ transition $\sim 2.24 \mathrm{eV}$ below the CBM) contributing no source of $\mathrm{p}$ or n-type conductivity in anatase. Due to the intrinsic n-type nature of anatase, the Fermi level is likely to exist toward the CBM and, as such, $\mathrm{N}_{\mathrm{O}}$ will act as an acceptor. Figure $3 \mathrm{a}$ displays the partial charge density for the neutral charge state of $\mathrm{N}_{\mathrm{O}}$ showing the hole localized on the $\mathrm{N}$ $2 \mathrm{p}$ orbital. These results are consistent with other HSE06 studies on $\mathrm{TiO}_{2}: \mathrm{N}^{38,39}$ Intrinsic compensation occurs from $\mathrm{V}_{\mathrm{O}}$ just around 0.34 and $0.25 \mathrm{eV}$ below the CBM for Ti-rich/Opoor and Ti-poor/O-rich conditions, respectively. In reality, under $\mathrm{O}$-rich conditions, this point would not be realizable due to the Fermi level being pinned in the band gap around 2.28 $\mathrm{eV}$ above the VBM from the crossing of $\mathrm{V}_{\mathrm{Ti}^{4-}}$ and $\mathrm{V}_{\mathrm{O}}^{2+}$.

Nitrogen relaxes from the "ideal" interstitial point to form a "split-interstitial" producing an $\mathrm{N}-\mathrm{O}$ dumbbell situated on an $\mathrm{O}$ atom site (denoted $(\mathrm{NO})_{\mathrm{O}}$ ). This behavior is observed in the previous theoretical literature and is supported by the presence of NO paramagnetic species in electron paramagnetic resonance (EPR). ${ }^{38,39,41-43,159}$ The formation energies of $(\mathrm{NO})_{\mathrm{O}}^{0}$ remain stable across the entirety of the chemical potential range with similar values of 4.48 and $4.73 \mathrm{eV}$ under Ti-rich/O-poor and Ti-poor/O-rich conditions, respectively. $(\mathrm{NO})_{\mathrm{O}}$, like $\mathrm{N}_{\mathrm{O}}$, can act as an electron acceptor and as a donor. At Fermi energies close to the VBM, (NO) 0 acts as a three-electron donor and becomes the dominant nitrogen species in $\mathrm{TiO}_{2}$. $(\mathrm{NO})_{\mathrm{O}}$ undergoes, a $3+/ 2+$ and a $2+/ 0$ transition level around 2.82 and $1.63 \mathrm{eV}$ below the CBM, respectively. In anatase, however, the Fermi level is likely to exist toward the $\mathrm{CBM}$ at which point $(\mathrm{NO})_{\mathrm{O}}$ acts as an acceptor. Despite having the ability to produce three holes in $\mathrm{TiO}_{2}$, (NO) $\mathrm{O}$ only undergoes one transition level in the band gap $(0 / 1-\text { transition at } 2.07 \mathrm{eV} \text { above the VBM). (NO })_{\mathrm{O}}$ can, therefore, be said to only accept one hole, consistent with the previous theory. ${ }^{38,41,42}$ Figure $3 \mathrm{~b}$ shows neutral charge state of (NO) $)_{\mathrm{O}}$ displaying the localized hole bound to the $\mathrm{N}-\mathrm{O}$ dumbbell. Under Ti-poor/O-rich conditions, it is likely that $(\mathrm{NO})_{\mathrm{O}}$ will be the dominant nitrogen species across the entirety of the band gap and explains the defect's appearance in the experimental literature. Under Ti-rich/O-poor, however, it is likely that a greater concentration of substitutional nitrogen will be seen when the Fermi level is trapped just below the CBM.

$\mathrm{Nb}$ and Ta Doping. $\mathrm{Nb}_{\mathrm{Ti}}$ and $\mathrm{Ta}_{\mathrm{Ti}}$ are the lowest formation energy defects under both growth regimes having formation energies of 0.38 and $0.22 \mathrm{eV}$, respectively, under Ti-rich/Opoor conditions. Under a Ti-poor/O-rich growth regime, the formation energies rise to 1.38 and $1.22 \mathrm{eV}$ for $\mathrm{Nb}_{\mathrm{Ti}}$ and $\mathrm{Ta} \mathrm{Ti}_{\mathrm{Ti}}$, 


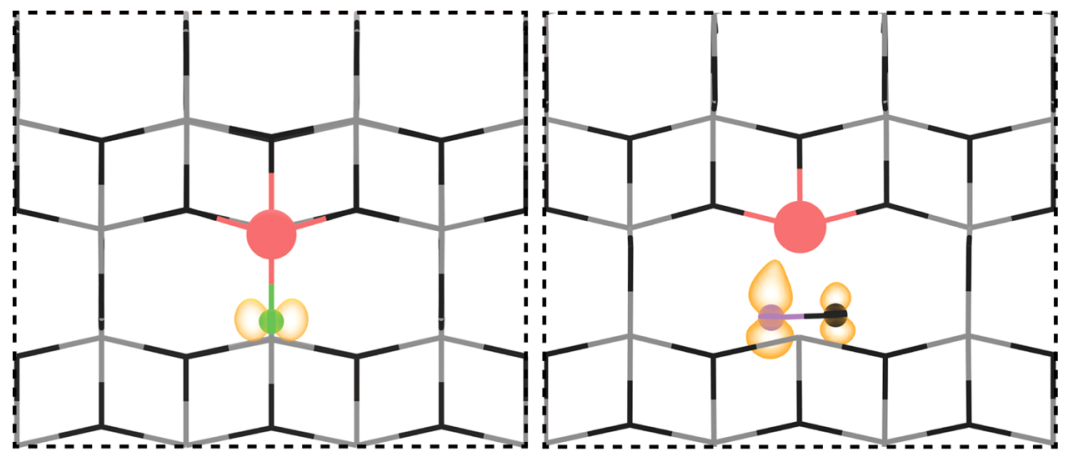

(a)

(b)

Figure 4. Partial charge densities for $(\mathrm{a})\left[\mathrm{Nb}(\mathrm{Ta})_{\mathrm{Ti}}+\mathrm{N}_{\mathrm{O}}\right]$ and $(\mathrm{b})\left[\mathrm{Nb}(\mathrm{Ta})_{\mathrm{Ti}}+(\mathrm{NO})_{\mathrm{O}}\right]$ as viewed along the $[100]$ direction. $\mathrm{The}$ anatase lattice is portrayed through the wire-frame model ( $\mathrm{Ti}=$ gray, $\mathrm{O}=$ black) and the dopant species by the colored spheres $($ colored coded to Figure 2 ). The electron partial charge density is shown in orange and is plotted from 0 to $0.02 \mathrm{eV}^{-3}$.

respectively. This is likely due to the similar ionic radii of $\mathrm{Nb}$ and $\mathrm{Ta}(\sim 64 \mathrm{pm})$ to $\mathrm{Ti}(\sim 61 \mathrm{pm})^{46}$ causing minimal strain to the anatase lattice upon incorporation of these dopants (the six surrounding $\mathrm{O}$ atoms move $\sim 1-1.5 \%$ away from the dopant center). Both substitutional $\mathrm{Nb}$ and $\mathrm{Ta}$ act as resonant donors donating one electron to the conduction band with the $1+/ 0$ transition levels occurring above the CBM. The electron density is, therefore, delocalized over the Ti $3 \mathrm{~d}$ orbitals that make up the CBM (Figure 3c). These results are indicative of the high conductivities seen in experiment $\mathrm{TiO}_{2}{ }^{10,158}$ and is reproduced in the theoretical literature. ${ }^{119,160,161}$ Under Tipoor/O-rich conditions, $\mathrm{Nb} / \mathrm{Ti}_{\mathrm{Ti}}$ is compensated for by $\mathrm{V}_{\mathrm{Ti}}^{4-}$ ca. 0.66 and $0.63 \mathrm{eV}$ below the $\mathrm{CBM}$ for $\mathrm{Nb}$ and $\mathrm{Ta}$, respectively. Under a Ti-rich/O-poor growth regime, however, no intrinsic compensation occurs in the band gap.

Realization of Fully Passivated Codoping? To assess the viability of fully passivated codoping in anatase $\mathrm{TiO}_{2}$, two different dopant clusters were tested in this study. It is clear from doping with $\mathrm{N}$ that under $\mathrm{O}$-poor conditions, $\mathrm{N}_{\mathrm{O}}$ is the dominant nitrogen defect across the band gap, and under $\mathrm{O}$ rich conditions, the interstitial $(\mathrm{NO})_{\mathrm{O}}$ dumbell is preferred. The dopant clusters proposed are thus: $\left[\mathrm{M}_{\mathrm{Ti}}+\mathrm{N}_{\mathrm{O}}\right]$ and $\left[\mathrm{M}_{\mathrm{Ti}}\right.$ $+(\mathrm{NO})_{\mathrm{O}}$ ] (where $\mathrm{M}=\mathrm{Nb}$ or $\mathrm{Ta}$ ). Despite interstitial nitrogen formally inducing three holes, due to the nature of the $\mathrm{N}-\mathrm{O}$ species, only one hole is available and acts as an acceptor at Fermi levels toward the CBM (as $(\mathrm{NO})_{\mathrm{O}}$ is in the $1-$ charge state). For full passivation of both clusters, only one substitutional $\mathrm{Nb}(\mathrm{Ta})$ defect is, therefore, required. Both defect clusters showed a preferential "near" configuration (by $\sim 0.13,0.04,0.18$, and $0.07 \mathrm{eV}$ for $\left[\mathrm{Nb}_{\mathrm{Ti}}+\mathrm{N}_{\mathrm{O}}\right],\left[\mathrm{Ta}_{\mathrm{Ti}}+\mathrm{N}_{\mathrm{O}}\right]$, $\left[\mathrm{Nb}_{\mathrm{Ti}}+(\mathrm{NO})_{\mathrm{O}}\right]$, and $\left[\mathrm{Ta}_{\mathrm{Ti}}+(\mathrm{NO})_{\mathrm{O}}\right]$, respectively) as is to be expected due to the Coulombic attraction. The thermodynamic transition levels show that $\mathrm{Nb}$ and $\mathrm{Ta}$ clusters possess very similar formation energies, which is to be expected considering the ionic radii ${ }^{46}$ and formation energies of the $\mathrm{Nb}_{\mathrm{Ti}}$ and $\mathrm{Ta}_{\mathrm{Ti}}$.

Under O-poor conditions, the $\left[\mathrm{Nb}(\mathrm{Ta})_{\mathrm{Ti}}+\mathrm{N}_{\mathrm{O}}\right]$ clusters possess a formation energy of $1.60 \mathrm{eV}(\mathrm{Ta}=1.53 \mathrm{eV})$ in the neutral charge state. The density of states (DOS) in SI Figure 2a,b shows the spin-up and spin-down occupied states around the Fermi level (for the cluster supercell) $(0.36$ and $0.41 \mathrm{eV}$ above the $\mathrm{VBM}$ for $[\mathrm{Nb}+\mathrm{N}]$ and $[\mathrm{Ta}+\mathrm{N}]$, respectively) which gives rise to the $1+$ and $2+$ charge states whereby each electron is removed. The two transition levels $(2+/ 1+$ and $1+/$ $0)$ for $\left[\mathrm{Nb}(\mathrm{Ta})_{\mathrm{Ti}}+\mathrm{N}_{\mathrm{O}}\right]$ occur in the band gap: the $2+/ 1+$ at $\sim 2.93 \mathrm{eV}(2.63 \mathrm{eV})$ and the $1+/ 0 \sim 1.95 \mathrm{eV}(1.89 \mathrm{eV})$ below the $\mathrm{CBM}$ for $\mathrm{Nb}$ and $(\mathrm{Ta})$, respectively. Under O-rich conditions, $\left[\mathrm{Nb}(\mathrm{Ta})_{\mathrm{Ti}}+\mathrm{N}_{\mathrm{O}}\right]$ possesses a relatively high formation energy of $4.86 \mathrm{eV}(4.79 \mathrm{eV})$.

$\left[\mathrm{Nb}(\mathrm{Ta})_{\mathrm{Ti}}+(\mathrm{NO})_{\mathrm{O}}\right]$ possesses relatively high formation energies under both $\mathrm{O}$-poor and $\mathrm{O}$-rich conditions of $3.47 \mathrm{eV}$ $(3.41 \mathrm{eV})$ and $4.73 \mathrm{eV}(4.67 \mathrm{eV})$, respectively, when in the neutral charge state. As with $\left[\mathrm{Nb}(\mathrm{Ta})_{\mathrm{Ti}}+\mathrm{N}_{\mathrm{O}}\right],\left[\mathrm{Nb}(\mathrm{Ta})_{\mathrm{Ti}}+\right.$ $\left.(\mathrm{NO})_{\mathrm{O}}\right]$ undergoes two transition levels in the band gap. The DOS for each cluster is shown in SI Figure 2c,d displaying a similar situation as with $\left[\mathrm{M}_{\mathrm{Ti}}+\mathrm{N}_{\mathrm{O}}\right]$ whereby the $\mathrm{N}$ and $\mathrm{O}$ states appear around $0.61 \mathrm{eV}$ above the VBM for both clusters, respectively. This can also be thought of as removing electrons from the antibonding $\pi$ orbital in an $\mathrm{N}-\mathrm{O}$ molecular orbital diagram. For the $\left[\mathrm{Nb}(\mathrm{Ta})_{\mathrm{Ti}}+(\mathrm{NO})_{\mathrm{O}}\right]$ cluster, the $2+/ 1+$ and $1+/ 0$ transitions occur at $2.93 \mathrm{eV}(2.94 \mathrm{eV})$ and $1.71 \mathrm{eV}(1.73$ $\mathrm{eV}$ ) below the $\mathrm{CBM}$, respectively, for the $\mathrm{Nb}$ and $(\mathrm{Ta})$ systems.

Figure 4a,b shows the partial charge densities for both $\left[\mathrm{M}_{\mathrm{Ti}}\right.$ $\left.+\mathrm{N}_{\mathrm{O}}\right](q=0)$ and $\left[\mathrm{M}_{\mathrm{Ti}}+(\mathrm{NO})_{\mathrm{O}}\right](q=0)$ (where $\mathrm{M}=\mathrm{Nb}$ and $\mathrm{Ta})$, respectively, for the filled states, as shown in the DOS in SI Figure 2. In Figure 4a, the localized hole is now passivated with the donated electron. The likely improvement in visible light activity in $\mathrm{TiO}_{2}$ is possibly due to the excitation of the electron in the filled $\mathrm{N}$ orbital to the CBM which occurs in visible light. ${ }^{38}$ A similar situation occurs in Figure $4 \mathrm{~b}$ whereby the delocalized hole state on the $\mathrm{N}-\mathrm{O}$ dumbbell is filled by the donated electron from $\mathrm{Nb}(\mathrm{Ta})_{\mathrm{Ti}}$.

Under Ti-rich/O-poor conditions, it is clear that when comparing the neutral charge states, the formation energy of nitrogen defects is reduced in the presence of substitutional $\mathrm{Nb}$ and Ta defects. Despite this, the defect clusters retain high formation energies compared to $\mathrm{Nb}_{\mathrm{Ti}}$ and $\mathrm{Ta}_{\mathrm{Ti}}$ and at Fermi levels at the CBM both $\mathrm{N}_{\mathrm{O}}$ and $(\mathrm{NO})_{\mathrm{O}}$ are both preferable (by 0.23 and $0.34 \mathrm{eV}$, respectively, for $[\mathrm{Nb}+\mathrm{N}]$ and by 0.16 and $0.28 \mathrm{eV}$, respectively, for $[\mathrm{Ta}+\mathrm{N}])$. Under Ti-poor/O-rich growth conditions, this effect is more pronounced and $\mathrm{N}_{\mathrm{O}}(q=$ $1-)$ and $(\mathrm{NO})_{\mathrm{O}}(q=1-)$ were lower in energy by 1.23 and $1.34 \mathrm{eV}$, respectively, for $[\mathrm{Nb}+\mathrm{N}]$ and by 1.16 and $1.28 \mathrm{eV}$ for $[\mathrm{Ta}+\mathrm{N}]$, respectively. This suggests that cluster formation will be negligible under thermodynamic equilibrium under all conditions.

Binding energies $\left(E_{\mathrm{BE}}\right)$ for the clusters were calculated using the equations 


$$
\begin{aligned}
E_{\mathrm{BE}}= & \Delta H_{\mathrm{f}}^{\mathrm{Nb}(\mathrm{Ta})_{\mathrm{Ti}}^{m}}+\Delta H_{\mathrm{f}}^{\mathrm{N}_{\mathrm{O}}^{n}}-\Delta H_{\mathrm{f}}^{\left[\mathrm{Nb}(\mathrm{Ta})+\mathrm{N}_{\mathrm{O}}\right]^{p}} \\
& +(m+n-p) E_{\mathrm{F}}
\end{aligned}
$$

and

$$
\begin{aligned}
E_{\mathrm{BE}}= & -\Delta H_{\mathrm{f}}^{\mathrm{Nb}(\mathrm{Ta})_{\mathrm{Ti}}^{m}}+\Delta H_{\mathrm{f}}^{(\mathrm{NO})_{\mathrm{o}}^{n}}-\Delta H_{\mathrm{f}}^{\left[\mathrm{Nb}(\mathrm{Ta})+(\mathrm{NO})_{\mathrm{o}}\right]^{p}} \\
& +(m+n-p) E_{\mathrm{F}}
\end{aligned}
$$

Where $\Delta H_{\mathrm{f}}^{[\mathrm{Nb}(\mathrm{Ta})+\mathrm{N}]^{p}}, \Delta H_{\mathrm{f}}^{\mathrm{Nb}(\mathrm{Ta})_{\mathrm{Ti}}^{m}}$, and $\Delta H_{\mathrm{f}}^{\mathrm{N}_{\mathrm{O}}^{n} \text { or }(\mathrm{NO})_{\mathrm{O}}^{n}}$ are the enthalpies of formation of the cluster and substitutional $\mathrm{Nb}(\mathrm{Ta})$ and $\mathrm{N}$, respectively. $p, m$, and $n$ refer to the charge states of each defect state and $E_{\mathrm{F}}$ is the Fermi energy. As $E_{\mathrm{F}}$ occurs around the CBM, the last term in this case is equal to 0 as $p=0, m=+1$, and $n=-1$, respectively. For each case, positive binding energies indicate the favorable formation of the defect clusters. The binding energies for $\left[\mathrm{Nb}_{\mathrm{Ti}}+\mathrm{N}_{\mathrm{O}}\right]$ and $\left[\mathrm{Ta}_{\mathrm{Ti}}+\mathrm{N}_{\mathrm{O}}\right]$ are 0.17 and $0.08 \mathrm{eV}$, respectively, indicating a small preference for complex formation, however, the formation energy difference between $\mathrm{N}_{\mathrm{O}}$ and the substitutional n-type defects is likely to significantly negate this effect such that no $1: 1$ compensation will occur. For $\left[\mathrm{Nb}_{\mathrm{Ti}}+(\mathrm{NO})_{\mathrm{O}}\right]$, a similarly small binding energy of $0.07 \mathrm{eV}$ exists; however for $\left[\mathrm{Ta}_{\mathrm{Ti}}+(\mathrm{NO})_{\mathrm{O}}\right]$, the binding energy is $-0.04 \mathrm{eV}$ indicating that the complex formation is unfavorable.

Defect and Carrier Concentrations. The calculated equilibrium defect and carrier concentrations as a function of temperature $(T)$ are shown in Figure 5 for the cases of $\mathrm{Nb}$ and $\mathrm{N}$ codoping (left panel) and $\mathrm{Ta}$ and $\mathrm{N}$ codoping (right panel). As can be seen from Figure $2, \mathrm{Nb}_{\mathrm{Ti}}$ and $\mathrm{Ta} \mathrm{a}_{\mathrm{Ti}}$ have very similar formation energies, as do the complexes involving the different metal dopants with $\mathrm{N}$ impurities. As a consequence, the concentrations for both cases are quite similar, although the
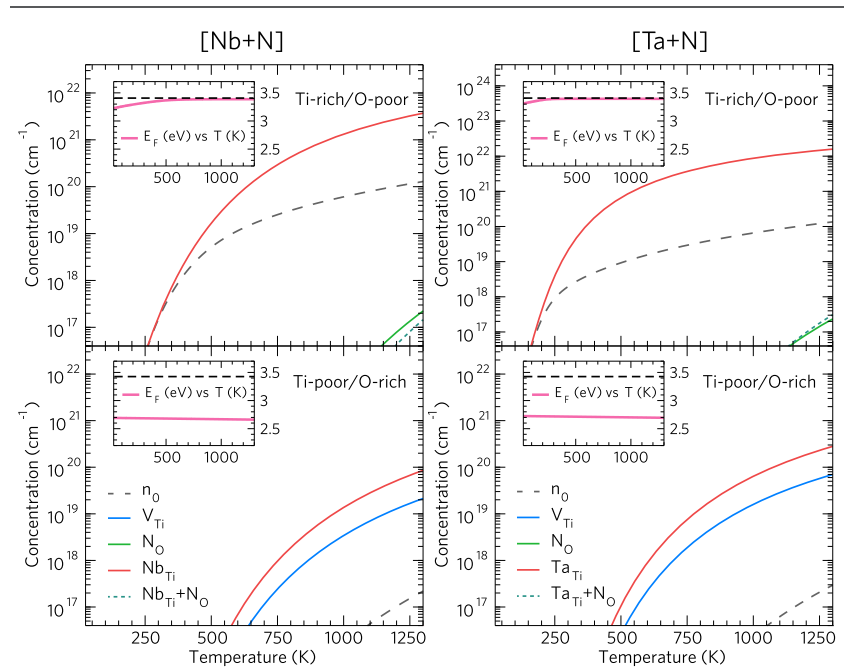

Figure 5. Equilibrium concentrations of metal impurities $\mathrm{M}_{\mathrm{Ti}}$ (red line, where $\mathrm{M}=\mathrm{Nb}$ or $\mathrm{Ta})$, titanium vacancies $\left(V_{\mathrm{Ti}}\right.$, blue line), substitutional $\mathrm{N}$ on $\mathrm{O}$ sites $\left(\mathrm{N}_{\mathrm{O}}\right.$, green line), complexes of substitutional nitrogen and metal impurities $\left(\mathrm{M}_{\mathrm{Ti}}+\mathrm{N}_{\mathrm{O}}\right.$, dotted teal line, where $\mathrm{M}=\mathrm{Nb}$ or $\mathrm{Ta})$ and electron carriers $\left(n_{0}\right.$, dashed orange line) calculated as a function of temperature. The left panel gives the concentrations for $\mathrm{Nb}$ doping, the right for $\mathrm{Ta}$ doping. The upper and lower panels correspond to O-poor and O-rich conditions, respectively. The insets show the self-consistent Fermi level $\left(E_{\mathrm{F}}\right.$, magenta line) as a function of temperature, with the zero of the energy scale set equal to the valence band maximum and the dashed line indicating the position of the conduction band minimum.
$\mathrm{Ta}_{\mathrm{Ti}}$ have slightly higher concentrations at each $T$ than the $\mathrm{Nb}_{\mathrm{Ti}}$ due to their lower formation energy (by $0.16 \mathrm{eV}$ ). From Figure 5, we see that in each case, the $\mathrm{Nb}_{\mathrm{Ti}}$ or $\mathrm{Ta}_{\mathrm{Ti}}$ impurities dominate, as expected from their low formation energies. Under O-poor conditions, the dopants are compensated predominantly by electron carriers, resulting in a strongly $\mathrm{n}$ type system, with $E_{\mathrm{F}}$ close to the conduction band minimum (see the insets). For the $\mathrm{Nb}$ case (Ta case) at $T>350 \mathrm{~K}(T>$ $250 \mathrm{~K}),\left[\mathrm{Nb}_{\mathrm{Ti}}\right]>n_{0}\left(\left[\mathrm{Ta}_{\mathrm{Ti}}\right]>n_{0}\right)$, indicating that the activation of the donor dopants reduces somewhat counterintuitively at higher $T$. The reason for this reduction is that, although at low $T$ the $1+$ charge state is most favorable and we have $\left[\mathrm{M}_{\mathrm{Ti}}\right] \approx\left[\mathrm{M}_{\mathrm{Ti}}^{1+}\right]=n_{0}($ where $\mathrm{M}=\mathrm{Nb}$ or $\mathrm{Ta})$, at higher $\mathrm{T}$ the 0 and $1-$ charge states become populated (as the $(1+/ 0)$ and $(0 / 1-)$ transitions occur close to the CBM), such that $\left[\mathrm{M}_{\mathrm{Ti}}\right]=\left[\mathrm{M}_{\mathrm{Ti}}^{1+}\right]+\left[\mathrm{M}_{\mathrm{Ti}}^{0}\right]+\left[\mathrm{M}_{\mathrm{Ti}}^{1-}\right]$, and $\left[\mathrm{M}_{\mathrm{Ti}}^{1+}\right]$ is charge balanced by $n_{0}+\left[\mathrm{M}_{\mathrm{Ti}}^{1-}\right]$. In O-rich conditions, the metal dopants are compensated by $V_{\mathrm{Ti}}^{4-}$, and $E_{\mathrm{F}}$ becomes trapped close to where the formation energies of the dopants and the vacancies are equal, at about $E_{\mathrm{F}}=2.7 \mathrm{eV}$ (see insets in the bottom panels of Figure 5). The system is, therefore, insulating under these conditions.

The most notable feature from Figure 5 is the lack of significant concentrations of $\mathrm{N}$ impurities across all values of $T$, which is a consequence of the relatively high formation energies of the related defects. This can, in part, be related back to equation 1 and the chemical potential limits imposed on the defects by $\mathrm{TiO}_{2}$. For the nitrogen-related defects, the cost of $\mathrm{N}-\mathrm{N}$ bond breaking is high, thus the change in $\mu_{\mathrm{N}}$ within the chemical potential limits of $\mathrm{TiO}_{2}$ is low compared to $\mu_{\mathrm{Ta}}$ or $\mu_{\mathrm{Nb}}$. Concentrations above $10^{17} \mathrm{~cm}^{-3}$ are only observed for $T>1200 \mathrm{~K}$, and we predict that many of those $\mathrm{N}$ atoms will be incorporated as complexes, but with significantly smaller concentrations than isolated $\mathrm{Nb}$ or $\mathrm{Ta}$ dopants, which act as shallow n-type donors. Note that in this analysis, we assume all defects are at the dilute limit, and we, therefore, do not include defect-defect interactions, but considering the low binding energies we calculate for the complexes, we expect that such interactions will have a minor effect on the computed concentrations. The key point is the relatively high formation energies of N-related defects, whether they be isolated or in complexes. Our results clearly demonstrate that $\mathrm{Nb}$ or $\mathrm{Ta}$ dopants will dominate, which results in an n-type system under O-poor conditions or an insulating system under O-rich conditions, due to the compensation by $V_{\mathrm{Ti}}$. Assuming defect formation occurs under thermodynamic equilibrium, the $\mathrm{N}$ dopants will only play a minor role in the defect chemistry.

\section{DISCUSSION}

The realization of fully passivated codoping in $[\mathrm{Nb}+\mathrm{N}]$ of $[\mathrm{Ta}+\mathrm{N}]$ codoped $\mathrm{TiO}_{2}$, however, is certainly unobtainable due to the inherent preference for n-type defects and dopants in anatase $\mathrm{TiO}_{2}$. As seen in Figures 2 and 5, under both growth regimes, substitutional $\mathrm{Nb}(\mathrm{Ta})$ are the dominant defects and are far lower in energy than any of the nitrogen or cluster species. The implication of this work is that although it is possible for the codoped clusters to form within the lattice (as shown by the binding energies), there will always be a higher concentration of n-type dopant and thus there will be no possibility to produce a fully passivated system. The lack of quantitative data on dopant concentrations in the previous experimental literature makes it impossible to ascertain whether full compensation has occurred. ${ }^{87,90,91,100,156,157}$ 
Certain studies do, however, acknowledge the lack of dopant parity such as those by Bartlett et al. and Chadwick et al. ${ }^{86,88,89}$ It should be noted that the majority of synthesis studies, which have attempted to produce codoped anatase $\mathrm{TiO}_{2}$, have utilized growth conditions that are nonequilibrium in nature, and where kinetic effects can play a large role. None of these methods, however, has managed to reach full passivation. Notably, CVD grown films of $[\mathrm{Nb}+\mathrm{N}]$ codoped $\mathrm{TiO}_{2}$, where kinetics are known to be hugely important, have failed to come close to full passivation. ${ }^{86}$

These results open up a further question: is compensated codoping of $\mathrm{TiO}_{2}$ possible at all? In terms of the other potential co-dopant pairs, $[\mathrm{W}+\mathrm{C}]$ and $[\mathrm{Mo}+\mathrm{C}]$, we consider that in both of these cases, the formation energy of the donor dopant will be much lower than that of any acceptor-based Crelated defect in anatase $\mathrm{TiO}_{2}$. Indeed, previous theoretical results have indicated that carbon interstitials are the dominant C-related defect under most growth conditions, and hence $\mathrm{C}$ will act as a donor and not as an acceptor in a compensated codoping pair which would raise the VBM of $\mathrm{TiO}_{2}$. These insights beg the question of whether passivated codoping as a band gap modification strategy in any material is achievable?

The answer to this question perhaps lies most simply in an analysis of the absolute band alignments of the band edges of the host system to be doped, relative to the vacuum level, Figure $6 . \mathrm{TiO}_{2}$ is a natively n-type semiconductor, with a large

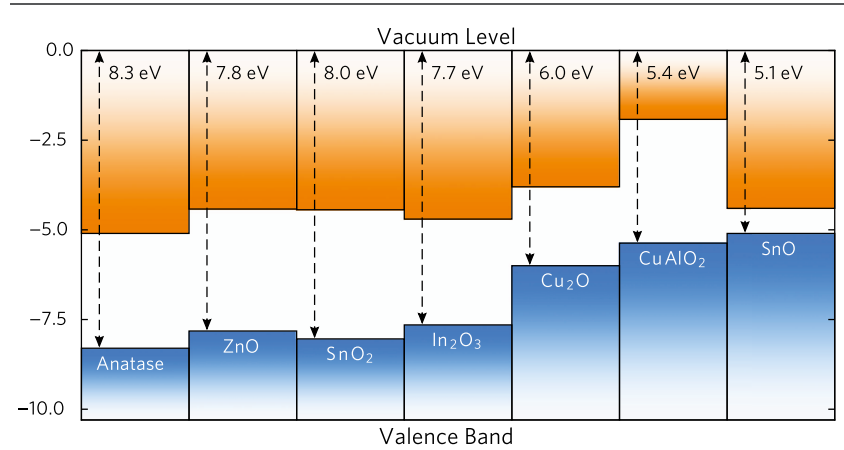

Figure 6. Band alignment of anatase $\mathrm{TiO}_{2}{ }^{164}$ compared to a selection of n-type and p-type semiconductors: $\mathrm{ZnO}^{165} \mathrm{SnO}_{2}{ }^{166} \mathrm{In}_{2} \mathrm{O}_{3}{ }^{167}$ $\mathrm{Cu}_{2} \mathrm{O},{ }^{168} \mathrm{CuAlO}_{2}{ }^{169} \mathrm{SnO} .{ }^{170}$ The ionization potentials for each compound are displayed relative to the vacuum level $(0 \mathrm{eV})$.

electron affinity and a large ionization potential (IP). Systems that share this type of band alignment are almost always n-type in nature, such as $\mathrm{SnO}_{2}, \mathrm{ZnO}, \mathrm{In}_{2} \mathrm{O}_{3}$, etc. It has been demonstrated repeatedly by both theory and experiment that p-type doping in these systems is not achievable. ${ }^{13,14,162,163}$ It follows that efforts to produce passivated codoping in these and similar systems would be fighting against thermodynamics, as the n-type dopant will always be dominant over the p-type dopant.

Materials with a lower IP display a higher probability of effective incorporation of acceptor type defects, as is seen for natively p-type materials, such as $\mathrm{Cu}_{2} \mathrm{O}, \mathrm{CuAlO}_{2}$, and SnO. ${ }^{171-175}$ These type of systems often possess large band gaps, however, which means that although VBM positions are perhaps more ideal relative to the redox potential for water splitting, the same problems of weak light absorption exist as in n-type $\mathrm{TiO}_{2}$, and effective passivated codoping to lower the CBM while retaining the VBM position would face the inverse of the problems that we run into for codoping of $\mathrm{TiO}_{2}$ i.e. p- type defects will dominate over n-type defects. It is, therefore, likely that in practice only a truly bipolar material, which can be successfully doped both n-type and p-type, could approach full passivation. An additional benefit of bipolar materials is that they generally possess band gaps that are already within the visible light active range, and so passivated codoping is not likely to be necessary. Therefore, the future for passivated codoping is quite unclear.

\section{CONCLUSIONS}

Using hybrid density functional theory, an analysis of the thermodynamic properties of two archetypal systems: [ Ta + $\mathrm{N}]$ and $[\mathrm{Nb}+\mathrm{N}]$ codoped anatase $\mathrm{TiO}_{2}$, has been undertaken demonstrating that passivated codoping of anatase $\mathrm{TiO}_{2}$ is not possible. Analyzing the defect chemistry of these systems demonstrates that a severe doping asymmetry arises due to the inherent n-type nature of anatase. This asymmetry always favors incorporation of a higher concentration of the electron donating dopant, meaning that full passivation is not achievable for a system grown at thermodynamic equilibrium.

\section{ASSOCIATED CONTENT}

\section{Supporting Information}

The Supporting Information is available free of charge on the ACS Publications website at DOI: 10.1021/acs.chemmater.9b00257.

Details of the limiting phases pertaining to the chemical potential limits, density of states (DOS) of the codoped clusters and formation energies under each growth regime together with transition levels relative to the VBM (PDF)

\section{AUTHOR INFORMATION}

\section{Corresponding Author}

*E-mail: d.scanlon@ucl.ac.uk.

ORCID

Benjamin A. D. Williamson: 0000-0002-6242-1121

Sanjayan Sathasivam: 0000-0002-5206-9558

Claire J. Carmalt: 0000-0003-1788-6971

David O. Scanlon: 0000-0001-9174-8601

\section{Notes}

The authors declare no competing financial interest.

\section{ACKNOWLEDGMENTS}

This work made use of the ARCHER U.K. National Supercomputing Service (http://www.archer.ac.uk) via our membership of the U.K.'s HEC Materials Chemistry Consortium, which is also funded by the EPSRC (EP/ L000202). B.A.D.W. would like to acknowledge the use of the "bapt" python-package by A. Ganose (https://github.com/utf/ bapt) to plot the band alignment in Figure 6. The UCL Legion and Grace HPC Facilities (Legion@UCL and Grace@UCL) were also used in the completion of this work. D.O.S, C.J.C., and I.P.P. would like to acknowledge support from the EPSRC (EP/N01572X/1). D.O.S. acknowledges support from the European Research Council, ERC, (grant no. 758345). We are grateful to the U.K. Materials and Molecular Modelling Hub for computational resources, which is partially funded by EPSRC (EP/P020194/1). 


\section{REFERENCES}

(1) Tayade, R. J.; Surolia, P. K.; Kulkarni, R. G.; Jasra, R. V. Photocatalytic Degradation of Dyes and Organic Contaminants in Water using Nanocrystalline Anatase and Rutile $\mathrm{TiO}_{2}$. Sci. Technol. Adv. Mater. 2007, 8, 455-462.

(2) Orlov, A.; Chan, M. S.; Jefferson, D. A.; Zhou, D.; Lynch, R. J.; Lambert, R. M. Photocatalytic Degradation of Water-Soluble Organic Pollutants on $\mathrm{TiO}_{2}$ Modified with Gold Nanoparticles. Environ. Technol. 2006, 27, 747-752.

(3) Yu, J. C.; Ho, W.; Lin, J.; Yip, H.; Wong, P. K. Photocatalytic Activity, Antibacterial Effect, and Photoinduced Hydrophilicity of $\mathrm{TiO}_{2}$ Films Coated on a Stainless Steel Substrate. Environ. Sci. Technol. 2003, 37, 2296-2301.

(4) Fu, G.; Vary, P. S.; Lin, C.-T. Anatase $\mathrm{TiO}_{2}$ Nanocomposites for Antimicrobial Coatings. J. Phys. Chem. B 2005, 109, 8889-8898.

(5) Dunnill, C. W.; Aiken, Z. A.; Pratten, J.; Wilson, M.; Morgan, D. J.; Parkin, I. P. Enhanced Photocatalytic Activity under Visible Light in N-doped $\mathrm{TiO}_{2}$ Thin Films Produced by APCVD Preparations using t-Butylamine as a Nitrogen Source and their Potential for Antibacterial Films. J. Photochem. Photobiol., A 2009, 207, 244-253.

(6) Page, K.; Wilson, M.; Parkin, I. P. Antimicrobial surfaces and their potential in reducing the role of the inanimate environment in the incidence of hospital-acquired infections. J. Mater. Chem. 2009, 19, 3819-3831.

(7) Walter, M. G.; Warren, E. L.; McKone, J. R.; Boettcher, S. W.; Mi, Q.; Santori, E. A.; Lewis, N. S. Solar Water Splitting Cells. Chem. Rev. 2010, 110, 6446-6473.

(8) Kudo, A.; Miseki, Y. Heterogeneous photocatalyst materials for water splitting. Chem. Soc. Rev. 2009, 38, 253-278.

(9) Xu, C.; Killmeyer, R.; Gray, M. L.; Khan, S. U. Enhanced carbon doping of $\mathrm{n}-\mathrm{TiO}_{2}$ thin films for photoelectrochemical water splitting. Electrochem. Commun. 2006, 8, 1650-1654.

(10) Bhachu, D. S.; Sathasivam, S.; Sankar, G.; Scanlon, D. O.; Cibin, G.; Carmalt, C. J.; Parkin, I. P.; Watson, G. W.; Bawaked, S. M.; Obaid, A. Y.; Al-Thabaiti, S.; Basahel, S. N. Solution Processing Route to Multifunctional Titania Thin Films: Highly Conductive and Photcatalytically Active $\mathrm{Nb}: \mathrm{TiO}_{2}$. Adv. Funct. Mater. 2014, 24, 50755085

(11) Walsh, A.; Ahn, K.-S.; Shet, S.; Huda, M. N.; Deutsch, T. G.; Wang, H.; Turner, J. A.; Wei, S.-H.; Yan, Y.; Al-Jassim, M. M. Ternary cobalt spinel oxides for solar driven hydrogen production: Theory and experiment. Energy Environ. Sci. 2009, 2, 774-782.

(12) Buckeridge, J.; Butler, K. T.; Catlow, C. R. A.; Logsdail, A. J.; Scanlon, D. O.; Shevlin, S. A.; Woodley, S. M.; Sokol, A. A.; Walsh, A. Polymorph Engineering of $\mathrm{TiO}_{2}$ : Demonstrating How Absolute Reference Potentials Are Determined by Local Coordination. Chem. Mater. 2015, 27, 3844-3851.

(13) Walsh, A.; Buckeridge, J.; Catlow, C. R. A.; Jackson, A. J.; Keal, T. W.; Miskufova, M.; Sherwood, P.; Shevlin, S. A.; Watkins, M. B.; Woodley, S. M.; Sokol, A. A. Limits to Doping of Wide Band Gap Semiconductors. Chem. Mater. 2013, 25, 2924-2926.

(14) Scanlon, D. O.; Watson, G. W. On the possibility of p-type $\mathrm{SnO}_{2}$. J. Mater. Chem. 2012, 22, 25236-25245.

(15) Williamson, B. A. D.; Buckeridge, J.; Brown, J.; Ansbro, S.; Palgrave, R. G.; Scanlon, D. O. Engineering Valence Band Dispersion for High Mobility p-Type Semiconductors. Chem. Mater. 2016, 29, 2402-2413.

(16) Asahi, R. Visible-Light Photocatalysis in Nitrogen-Doped Titanium Oxides. Science 2001, 293, 269-271.

(17) Sakthivel, S.; Janczarek, M.; Kisch, H. Visible Light Activity and Photoelectrochemical Properties of Nitrogen-Doped $\mathrm{TiO}_{2}$. J. Phys. Chem. B 2004, 108, 19384-19387.

(18) Finazzi, E.; Di Valentin, C.; Pacchioni, G. Boron-Doped AnataseTiO $\mathrm{T}_{2}$ : Pure and Hybrid DFT Calculations. J. Phys. Chem. C 2009, 113, 220-228.

(19) Wu, X.; Yin, S.; Dong, Q.; Guo, C.; Li, H.; Kimura, T.; Sato, T. Synthesis of high visible light active carbon doped $\mathrm{TiO}_{2}$ photocatalyst by a facile calcination assisted solvothermal method. Appl. Catal., $B$ 2013, 142-143, 450-457.
(20) Sotelo-Vazquez, C.; Noor, N.; Kafizas, A.; Quesada-Cabrera, R.; Scanlon, D. O.; Taylor, A.; Durrant, J. R.; Parkin, I. P. Multifunctional P-Doped $\mathrm{TiO}_{2}$ Films: A New Approach to SelfCleaning, Transparent Conducting Oxide Materials. Chem. Mater. 2015, 27, 3234-3242.

(21) Quesada-González, M.; Boscher, N. D.; Carmalt, C. J.; Parkin, I. P. Interstitial Boron-Doped $\mathrm{TiO}_{2}$ Thin Films: The Significant Effect of Boron on $\mathrm{TiO}_{2}$ Coatings Grown by Atmospheric Pressure Chemical Vapor Deposition. ACS Appl. Mater. Interfaces 2016, 8, 25024-25029.

(22) Wang, B.; Zhao, F.; Du, G.; Porter, S.; Liu, Y.; Zhang, P.; Cheng, Z.; Liu, H. K.; Huang, Z. Boron-Doped Anatase $\mathrm{TiO}_{2}$ as a High-Performance Anode Material for Sodium-Ion Batteries. ACS Appl. Mater. Interfaces 2016, 8, 16009-16015.

(23) Grabowska, E.; Zaleska, A.; Sobczak, J.; Gazda, M.; Hupka, J. Boron-doped $\mathrm{TiO}_{2}$ : Characteristics and photoactivity under visible light. Procedia Chem. 2009, 1, 1553-1559.

(24) Yang, Y.; Ni, D.; Yao, Y.; Zhong, Y.; Ma, Y.; Yao, J. High photocatalytic activity of carbon doped $\mathrm{TiO}_{2}$ prepared by fast combustion of organic capping ligands. RSC Adv. 2015, 5, 9363593643.

(25) Wu, G.; Nishikawa, T.; Ohtani, B.; Chen, A. Synthesis and Characterization of Carbon-Doped $\mathrm{TiO}_{2}$ Nanostructures with Enhanced Visible Light Response. Chem. Mater. 2007, 19, 45304537.

(26) Park, Y.; Kim, W.; Park, H.; Tachikawa, T.; Majima, T.; Choi, W. Carbon-doped $\mathrm{TiO}_{2}$ photocatalyst synthesized without using an external carbon precursor and the visible light activity. Appl. Catal., $B$ 2009, 91, 355-361.

(27) Sathish, M.; Viswanathan, B.; Viswanath, R. P.; Gopinath, C. S. Synthesis, Characterization, Electronic Structure, and Photocatalytic Activity of Nitrogen-Doped $\mathrm{TiO}_{2}$ Nanocatalyst. Chem. Mater. 2005, $17,6349-6353$.

(28) Cong, Y.; Zhang, J.; Chen, F.; Anpo, M. Synthesis and Characterization of Nitrogen-Doped $\mathrm{TiO}_{2}$ Nanophotocatalyst with High Visible Light Activity. J. Phys. Chem. C 2007, 111, 6976-6982.

(29) Gopal, N. O.; Lo, H.-H.; Ke, T.-F.; Lee, C.-H.; Chou, C.-C.; Wu, J.-D.; Sheu, S.-C.; Ke, S.-C. Visible Light Active PhosphorusDoped $\mathrm{TiO}_{2}$ Nanoparticles: An EPR Evidence for the Enhanced Charge Separation. J. Phys. Chem. C 2012, 116, 16191-16197.

(30) Shi, J.; Chen, S.; Wang, S.; Ye, Z. Sol-Gel Preparation and Visible Light Photocatalytic Activity of Nitrogen Doped Titania. Procedia Eng. 2012, 27, 564-569.

(31) Ai, H.-Y.; Shi, J.-W.; Duan, R.-X.; Chen, J.-W.; Cui, H.-J.; Fu, M.-L. Sol-Gel to Prepare Nitrogen Doped $\mathrm{TiO}_{2}$ Nanocrystals with Exposed $\{001\}$ Facets and High Visible-Light Photocatalytic Performance. Int. J. Photoenergy 2014, 2014, 1-9.

(32) Quesada-Cabrera, R.; Sotelo-Vázquez, C.; Quesada-González, M.; Melián, E. P.; Chadwick, N.; Parkin, I. P. On the apparent visiblelight and enhanced UV-light photocatalytic activity of nitrogen-doped $\mathrm{TiO}_{2}$ thin films. J. Photochem. Photobiol., A 2017, 333, 49-55.

(33) Kim, S. J.; Xu, K.; Parala, H.; Beranek, R.; Bledowski, M.; Sliozberg, K.; Becker, H.-W.; Rogalla, D.; Barreca, D.; Maccato, C.; Sada, C.; Schuhmann, W.; Fischer, R. A.; Devi, A. Intrinsic Nitrogendoped CVD-grown $\mathrm{TiO}_{2}$ Thin Films from All-N-coordinated $\mathrm{Ti}$ Precursors for Photoelectrochemical Applications. Chem. Vap. Deposition 2013, 19, 45-52.

(34) Sarantopoulos, C.; Gleizes, A. N.; Maury, F. Chemical vapor deposition and characterization of nitrogen doped $\mathrm{TiO}_{2}$ thin films on glass substrates. Thin Solid Films 2009, 518, 1299-1303.

(35) Chen, S.-Z.; Zhang, P.-Y.; Zhuang, D.-M.; Zhu, W.-P. Investigation of nitrogen doped $\mathrm{TiO}_{2}$ photocatalytic films prepared by reactive magnetron sputtering. Catal. Commun. 2004, 5, 677-680.

(36) Prabakar, K.; Takahashi, T.; Nezuka, T.; Takahashi, K.; Nakashima, T.; Kubota, Y.; Fujishima, A. Visible light-active nitrogendoped $\mathrm{TiO}_{2}$ thin films prepared by DC magnetron sputtering used as a photocatalyst. Renewable Energy 2008, 33, 277-281.

(37) Pandiyan, R.; Delegan, N.; Dirany, A.; Drogui, P.; Khakani, M. A. E. Probing the Electronic Surface Properties and Bandgap 
Narrowing of in situ N, W, and $(\mathrm{W}, \mathrm{N})$ Doped Magnetron-Sputtered $\mathrm{TiO}_{2}$ Films Intended for Electro-Photocatalytic Applications. J. Phys. Chem. C 2016, 120, 631-638.

(38) Varley, J. B.; Janotti, A.; de Walle, C. G. V. Mechanism of Visible-Light Photocatalysis in Nitrogen-Doped $\mathrm{TiO}_{2}$. Adv . Mater. 2011, 23, 2343-2347.

(39) Chen, H.; Dawson, J. A. Nature of Nitrogen-Doped Anatase $\mathrm{TiO}_{2}$ and the Origin of Its Visible-Light Activity. J. Phys. Chem. C 2015, 119, 15890-15895.

(40) Finazzi, E.; Di Valentin, C.; Selloni, A.; Pacchioni, G. First Principles Study of Nitrogen Doping at the Anatase $\mathrm{TiO}_{2}$ (101) Surface. J. Phys. Chem. C 2007, 111, 9275-9282.

(41) Livraghi, S.; Paganini, M. C.; Giamello, E.; Selloni, A.; Di Valentin, C.; Pacchioni, G. Origin of Photoactivity of Nitrogen-Doped Titanium Dioxide under Visible Light. J. Am. Chem. Soc. 2006, 128, $15666-15671$.

(42) Di Valentin, C.; Finazzi, E.; Pacchioni, G.; Selloni, A.; Livraghi, S.; Paganini, M. C.; Giamello, E. N-doped $\mathrm{TiO}_{2}$ : Theory and experiment. Chem. Phys. 2007, 339, 44-56.

(43) Di Valentin, C.; Pacchioni, G.; Selloni, A.; Livraghi, S.; Giamello, E. Characterization of Paramagnetic Species in N-Doped $\mathrm{TiO}_{2}$ Powders by EPR Spectroscopy and DFT Calculations. J. Phys. Chem. B 2005, 109, 11414-11419.

(44) Gai, Y.; Li, J.; Li, S.-S.; Xia, J.-B.; Wei, S.-H. Design of NarrowGap $\mathrm{TiO}_{2}$ : A Passivated Codoping Approach for Enhanced Photoelectrochemical Activity. Phys. Rev. Lett. 2009, 102, No. 036402.

(45) Bharti, B.; Kumar, S.; Lee, H.-N.; Kumar, R. Formation of oxygen vacancies and $\mathrm{Ti}^{3+}$ state in $\mathrm{TiO}_{2}$ thin film and enhanced optical properties by air plasma treatment. Sci. Rep. 2016, 6, No. 32355.

(46) Shannon, R. D. Revised effective ionic radii and systematic studies of interatomic distances in halides and chalcogenides. Acta Crystallogr., Sect. A: Cryst. Phys., Diffr., Theor. Gen. Crystallogr. 1976, 32, 751-767.

(47) Li, Y.; Hwang, D.-S.; Lee, N. H.; Kim, S.-J. Synthesis and characterization of carbon-doped titania as an artificial solar light sensitive photocatalyst. Chem. Phys. Lett. 2005, 404, 25-29.

(48) Di Valentin, C.; Pacchioni, G.; Selloni, A. Theory of Carbon Doping of Titanium Dioxide. Chem. Mater. 2005, 17, 6656-6665.

(49) Sun, Y.-Y.; Zhang, S. Kinetics stabilized doping: computational optimization of carbon-doped anatase $\mathrm{TiO}_{2}$ for visible-light driven water splitting. Phys. Chem. Chem. Phys. 2016, 18, 2776-2783.

(50) Sakthivel, S.; Kisch, H. Daylight Photocatalysis by CarbonModified Titanium Dioxide. Angew. Chem., Int. Ed. 2003, 42, 49084911.

(51) Sharma, S. D.; Singh, D.; Saini, K.; Kant, C.; Sharma, V.; Jain, S.; Sharma, C. Sol-gel-derived super-hydrophilic nickel doped $\mathrm{TiO}_{2}$ film as active photo-catalyst. Appl. Catal., A 2006, 314, 40-46.

(52) Janisch, R.; Gopal, P.; Spaldin, N. A. Transition metal-doped $\mathrm{TiO}_{2}$ and $\mathrm{ZnO}$ - present status of the field. J. Phys.: Condens. Matter 2005, 17, R657-R689.

(53) Tian, J.; Gao, H.; Deng, H.; Sun, L.; Kong, H.; Yang, P.; Chu, J. Structural, magnetic and optical properties of Ni-doped $\mathrm{TiO}_{2}$ thin films deposited on silicon(100) substrates by sol-gel process. J. Alloys Compd. 2013, 581, 318-323.

(54) Al-Jawad, S. M.; Taha, A. A.; Salim, M. M. Synthesis and characterization of pure and $\mathrm{Fe}$ doped $\mathrm{TiO}_{2}$ thin films for antimicrobial activity. Optik 2017, 142, 42-53.

(55) Mathews, N. R.; Jacome, M. A. C.; Morales, E. R.; Antonio, J. A. T. Structural and spectroscopic study of the $\mathrm{Fe}$ doped $\mathrm{TiO}_{2}$ thin films for applications in photocatalysis. Phys. Status Solidi C 2009, 6, S219-S223.

(56) Wang, X.; Gong, W. Bactericidal and Photocatalytic Activity of $\mathrm{Fe}^{3}-\mathrm{TiO}_{2}$ Thin Films Prepared by the Sol-Gel Method. J. Wuhan Univ. Technol., Mater. Sci. Ed. 2008, 23, 155-158.

(57) Alexandrescu, R.; Morjan, I.; Scarisoreanu, M.; Birjega, R.; Popovici, E.; Soare, I.; Gavrila-Florescu, L.; Voicu, I.; Sandu, I.; Dumitrache, F.; Prodan, G.; Vasile, E.; Figgemeier, E. Structural investigations on $\mathrm{TiO}_{2}$ and $\mathrm{Fe}$-doped $\mathrm{TiO}_{2}$ nanoparticles synthesized by laser pyrolysis. Thin Solid Films 2007, 515, 8438-8445.

(58) Sadanandam, G.; Lalitha, K.; Kumari, V. D.; Shankar, M. V.; Subrahmanyam, M. Cobalt doped $\mathrm{TiO}_{2}$ : A stable and efficient photocatalyst for continuous hydrogen production from glycerol: Water mixtures under solar light irradiation. Int. J. Hydrogen Energy 2013, 38, 9655-9664.

(59) Iwasaki, M.; Hara, M.; Kawada, H.; Tada, H.; Ito, S. Cobalt Ion-Doped $\mathrm{TiO}_{2}$ Photocatalyst Response to Visible Light. J. Colloid Interface Sci. 2000, 224, 202-204.

(60) Miao, Y.; Zhai, Z.; Jiang, L.; Shi, Y.; Yan, Z.; Duan, D.; Zhen, K.; Wang, J. Facile and new synthesis of cobalt doped mesoporous $\mathrm{TiO}_{2}$ with high visible-light performance. Powder Technol. 2014, 266, 365-371.

(61) Ould-Chikh, S.; Proux, O.; Afanasiev, P.; Khrouz, L.; Hedhili, M. N.; Anjum, D. H.; Harb, M.; Geantet, C.; Basset, J.-M.; Puzenat, E. Photocatalysis with Chromium-Doped $\mathrm{TiO}_{2}$ : Bulk and Surface Doping. ChemSusChem 2014, 7, 1361-1371.

(62) Peng, Y.-H.; Huang, G.-F.; Huang, W.-Q. Visible-light absorption and photocatalytic activity of Cr-doped $\mathrm{TiO}_{2}$ nanocrystal films. Adv. Powder Technol. 2012, 23, 8-12.

(63) Dholam, R.; Patel, N.; Adami, M.; Miotello, A. Hydrogen production by photocatalytic water-splitting using $\mathrm{Cr}$ - or $\mathrm{Fe}$-doped $\mathrm{TiO}_{2}$ composite thin films photocatalyst. Int. J. Hydrogen Energy 2009, $34,5337-5346$.

(64) Jun, T. H.; Lee, K. S. Cr-doped $\mathrm{TiO}_{2}$ thin films deposited by RF-sputtering. Mater. Lett. 2010, 64, 2287-2289.

(65) You, M.; Kim, T. G.; Sung, Y.-M. Synthesis of Cu-Doped $\mathrm{TiO}_{2}$ Nanorods with Various Aspect Ratios and Dopant Concentrations. Cryst. Growth Des. 2010, 10, 983-987.

(66) Colón, G.; Maicu, M.; Hidalgo, M.; Navío, J. Cu-doped $\mathrm{TiO}_{2}$ systems with improved photocatalytic activity. Appl. Catal., B 2006, $67,41-51$

(67) Choudhury, B.; Dey, M.; Choudhury, A. Defect generation, d-d transition, and band gap reduction in $\mathrm{Cu}$-doped $\mathrm{TiO}_{2}$ nanoparticles. Int. Nano Lett. 2013, 3, No. 25.

(68) Park, H. S.; Kim, D. H.; Kim, S. J.; Lee, K. S. The photocatalytic activity of 2.5 wt \% Cu-doped $\mathrm{TiO}_{2}$ nano powders synthesized by mechanical alloying. J. Alloys Compd. 2006, 415, 51-55.

(69) Choi, W.; Termin, A.; Hoffmann, M. R. The Role of Metal Ion Dopants in Quantum-Sized $\mathrm{TiO}_{2}$ : Correlation between Photoreactivity and Charge Carrier Recombination Dynamics. J. Phys. Chem. 1994, 98, 13669-13679.

(70) Fagan, R.; McCormack, D. E.; Dionysiou, D. D.; Pillai, S. C. A review of solar and visible light active $\mathrm{TiO}_{2}$ photocatalysis for treating bacteria, cyanotoxins and contaminants of emerging concern. Mater. Sci. Semicond. Process. 2016, 42, 2-14.

(71) Zaleska, A. Doped-TiO ${ }_{2}$ : A Review. Recent Pat. Eng. 2008, 2, 157-164.

(72) Schneider, J.; Matsuoka, M.; Takeuchi, M.; Zhang, J.; Horiuchi, Y.; Anpo, M.; Bahnemann, D. W. Understanding $\mathrm{TiO}_{2}$ Photocatalysis: Mechanisms and Materials. Chem. Rev. 2014, 114, 9919-9986.

(73) Linsebigler, A. L.; Lu, G.; Yates, J. T. Photocatalysis on $\mathrm{TiO}_{2}$ Surfaces: Principles, Mechanisms, and Selected Results. Chem. Rev. 1995, 95, 735-758.

(74) Kafizas, A.; Dunnill, C. W.; Parkin, I. P. Combinatorial atmospheric pressure chemical vapour deposition (cAPCVD) of niobium doped anatase; effect of niobium on the conductivity and photocatalytic activity. J. Mater. Chem. 2010, 20, 8336-8349.

(75) Alim, M. A.; Bak, T.; Atanacio, A. J.; Ionescu, M.; Kennedy, B.; Price, W. S.; Plessis, J. D.; Pourmahdavi, M.; Zhou, M.; Torres, A.; Nowotny, J. Photocatalytic properties of Ta-doped $\mathrm{TiO}_{2}$. Ionics 2017, 23, 3517-3531.

(76) Znad, H.; Ang, M. H.; Tade, M. O. Ta/Ti-and Nb/Ti-Mixed Oxides as Efficient Solar Photocatalysts: Preparation, Characterization, and Photocatalytic Activity. Int. J. Photoenergy 2012, 2012, 19.

(77) Kelly, P.; West, G.; Ratova, M.; Fisher, L.; Ostovarpour, S.; Verran, J. Structural Formation and Photocatalytic Activity of 
Magnetron Sputtered Titania and Doped-Titania Coatings. Molecules 2014, 19, 16327-16348.

(78) Moon, J.; Takagi, H.; Fujishiro, Y.; Awano, M. Preparation and characterization of the Sb-doped $\mathrm{TiO}_{2}$ photocatalysts. J. Mater. Sci. 2001, 36, 949-955.

(79) Luo, L.; Li, T.; Ran, X.; Wang, P.; Guo, L. Probing Photocatalytic Characteristics of Sb-DopedTiO2under Visible Light Irradiation. J. Nanomater. 2014, 2014, 1-6.

(80) Sathasivam, S.; Bhachu, D. S.; Lu, Y.; Chadwick, N.; Althabaiti, S. A.; Alyoubi, A. O.; Basahel, S. N.; Carmalt, C. J.; Parkin, I. P. Tungsten Doped $\mathrm{TiO}_{2}$ with Enhanced Photocatalytic and Optoelectrical Properties via Aerosol Assisted Chemical Vapor Deposition. Sci. Rep. 2015, 5, No. 10952.

(81) Putta, T.; Lu, M.-C.; Anotai, J. Photocatalytic activity of tungsten-doped $\mathrm{TiO}_{2}$ with hydrothermal treatment under blue light irradiation. J. Environ. Manage. 2011, 92, 2272-2276.

(82) Sheppard, L. R.; Hager, S.; Holik, J.; Liu, R.; Macartney, S.; Wuhrer, R. Tantalum Segregation in Ta-Doped $\mathrm{TiO}_{2}$ and the Related Impact on Charge Separation during Illumination. J. Phys. Chem. C 2014, 119, 392-400.

(83) Bhachu, D. S.; Egdell, R. G.; Sankar, G.; Carmalt, C. J.; Parkin, I. P. Electronic properties of antimony-doped anatase $\mathrm{TiO}_{2}$ thin films prepared by aerosol assisted chemical vapour deposition. J. Mater. Chem. C 2017, 5, 9694-9701.

(84) Yin, W.-J.; Tang, H.; Wei, S.-H.; Al-Jassim, M. M.; Turner, J.; Yan, Y. Band structure engineering of semiconductors for enhanced photoelectrochemical water splitting: The case $\mathrm{TiO}_{2}$. Phys. Rev. B 2010, 82, No. 045106.

(85) Zhang, P.; Yin, S.; Sekino, T.; Lee, S. W.; Sato, T. Nb and N codoped $\mathrm{TiO}_{2}$ for a high-performance deNOx photocatalyst under visible LED light irradiation. Res. Chem. Intermed. 2012, 39, 15091515.

(86) Chadwick, N. P.; Glover, E. N. K.; Sathasivam, S.; Basahel, S. N.; Althabaiti, S. A.; Alyoubi, A. O.; Parkin, I. P.; Carmalt, C. J. Photoactivity and low resistivity in $\mathrm{N} / \mathrm{Nb}$ Codoped $\mathrm{TiO}_{2}$ thin films by combinatorial AACVD. J. Mater. Chem. A 2016, 4, 407-415.

(87) Lim, J.; Murugan, P.; Lakshminarasimhan, N.; Kim, J. Y.; Lee, J. S.; Lee, S.-H.; Choi, W. Synergic photocatalytic effects of nitrogen and niobium codoping in $\mathrm{TiO}_{2}$ for the redox conversion of aquatic pollutants under visible light. J. Catal. 2014, 310, 91-99.

(88) Breault, T. M.; Bartlett, B. M. Lowering the Band Gap of Anatase-Structured $\mathrm{TiO}_{2}$ by Coalloying with $\mathrm{Nb}$ and $\mathrm{N}$ : Electronic Structure and Photocatalytic Degradation of Methylene Blue Dye. J. Phys. Chem. C 2012, 116, 5986-5994.

(89) Breault, T. M.; Bartlett, B. M. Composition Dependence of $\mathrm{TiO}_{2}$ : $(\mathrm{Nb}, \mathrm{N})$-Compounds on the Rate of Photocatalytic Methylene Blue Dye Degradation. J. Phys. Chem. C 2013, 117, 8611-8618.

(90) Zhao, Y. F.; Li, C.; Hu, J. Y.; Gong, Y. Y.; Niu, L. Y.; Liu, X. J. $\mathrm{Ta}$ and $\mathrm{N}$ modulated electronic, optical and photocatalytic properties of $\mathrm{TiO}_{2}$. Phys. Lett. A 2016, 380, 910-916.

(91) Obata, K.; Irie, H.; Hashimoto, K. Enhanced photocatalytic activities of $\mathrm{Ta}, \mathrm{N}$ codoped $\mathrm{TiO}_{2}$ thin films under visible light. Chem. Phys. 2007, 339, 124-132.

(92) McDonnell, K. A.; English, N. J.; Rahman, M.; Dowling, D. P. Influence of doping on the photoactive properties of magnetronsputtered titania coatings: Experimental and theoretical study. Phys. Rev. B 2012, 86, No. 115306.

(93) Dong, P.; Liu, B.; Wang, Y.; Pei, H.; Yin, S. Enhanced photocatalytic activity of (Mo, C)-codoped anatase $\mathrm{TiO}_{2}$ nanoparticles for degradation of methyl orange under simulated solar irradiation. J. Mater. Res. 2010, 25, 2392-2400.

(94) Yang, F.; Yang, H.; Tian, B.; Zhang, J.; He, D. Preparation of an Mo and C codoped $\mathrm{TiO}_{2}$ catalyst by a calcination-hydrothermal method, and degradation of rhodamine B in visible light. Res. Chem. Intermed. 2012, 39, 1685-1699.

(95) Zhang, J.; Pan, C.; Fang, P.; Wei, J.; Xiong, R. Codoped $\mathrm{TiO}_{2}$ Using Thermal Oxidation for Enhancing Photocatalytic Activity. ACS Appl. Mater. Interfaces 2010, 2, 1173-1176.
(96) Zhe-Peng, Z.; Biao, Y.; Hai-Bo, F.; Xin-Liang, Z.; He-Bao, Y. Visible-light photocatalytic properties of $\mathrm{Mo}-\mathrm{C}$ codoped anatase $\mathrm{TiO}_{2}$ films prepared by magnetron sputtering. J. Phys. Chem. Solids 2015, 87, 53-57.

(97) Li, Z.; Wang, X.; Xing, X.; Wang, Y. Tailoring the electronic structure of anatase $\mathrm{TiO}_{2}(001)$ surface through $\mathrm{W}$ and $\mathrm{N}$ codoping: a DFT calculation. J. Korean Phys. Soc. 2017, 70, 286-291.

(98) Ren, D.; Cheng, J.; Cheng, X. Ab initio studies of Nb-N-S tridoped $\mathrm{TiO}_{2}$ with enhanced visible light photocatalytic activity. J. Solid State Chem. 2016, 238, 83-87.

(99) Choi, H.; Shin, D.; Yeo, B. C.; Song, T.; Han, S. S.; Park, N.; Kim, S. Simultaneously Controllable Doping Sites and the Activity of a W-N Codoped $\mathrm{TiO}_{2}$ Photocatalyst. ACS Catal. 2016, 6, 27452753.

(100) Rimoldi, L.; Ambrosi, C.; Liberto, G. D.; Presti, L. L.; Ceotto, M.; Oliva, C.; Meroni, D.; Cappelli, S.; Cappelletti, G.; Soliveri, G.; Ardizzone, S. Impregnation versus Bulk Synthesis: How the Synthetic Route Affects the Photocatalytic Efficiency of $\mathrm{Nb} / \mathrm{Ta}: \mathrm{N}$ Codoped $\mathrm{TiO}_{2}$ Nanomaterials. J. Phys. Chem. C 2015, 119, 24104-24115.

(101) Gong, J.; Yang, C.; Zhang, J.; Pu, W. Origin of Photocatalytic Activity of W/N-Codoped $\mathrm{TiO}_{2} \mathrm{H}_{2}$ Production and DFT Calculation with GGA+U. Appl. Catal., B 2014, 152-153, 73-81.

(102) Patel, N.; Jaiswal, R.; Warang, T.; Scarduelli, G.; Dashora, A.; Ahuja, B.; Kothari, D.; Miotello, A. Efficient photocatalytic degradation of organic water pollutants using $\mathrm{V}-\mathrm{N}$-codoped $\mathrm{TiO}_{2}$ thin films. Appl. Catal., B 2014, 150-151, 74-81.

(103) Fang, Y.; Cheng, D.; Niu, M.; Yi, Y.; Wu, W. Tailoring the Electronic and Optical Properties of Rutile $\mathrm{TiO}_{2}$ by $(\mathrm{Nb}+\mathrm{Sb}, \mathrm{C})$ Codoping from DFT + U Calculations. Chem. Phys. Lett. 2013, 567, 34-38.

(104) Huang, J.; Wen, S.; Liu, J.; He, G. Band gap narrowing of $\mathrm{TiO}_{2}$ by compensated codoping for enhanced photocatalytic activity. J. Nat. Gas Chem. 2012, 21, 302-307.

(105) Kurtoglu, M. E.; Longenbach, T.; Sohlberg, K.; Gogotsi, Y. Strong Coupling of $\mathrm{Cr}$ and $\mathrm{N}$ in $\mathrm{Cr}-\mathrm{N}$-doped $\mathrm{TiO}_{2}$ and Its Effect on Photocatalytic Activity. J. Phys. Chem. C 2011, 115, 17392-17399.

(106) Liu, L.; Chen, S.; Sun, W.; Xin, J. Enhancing the visible light absorption via combinational doping of $\mathrm{TiO}_{2}$ with nitrogen $(\mathrm{N})$ and chromium (Cr). J. Mol. Struct. 2011, 1001, 23-28.

(107) Di Valentin, C.; Finazzi, E.; Pacchioni, G.; Selloni, A.; Livraghi, S.; Czoska, A. M.; Paganini, M. C.; Giamello, E. Density Functional Theory and Electron Paramagnetic Resonance Study on the Effect of N-F Codoping of $\mathrm{TiO}_{2}$. Chem. Mater. 2008, 20, 37063714.

(108) Long, R.; English, N. J. Band gap engineering of (N,Ta)codoped $\mathrm{TiO}_{2}$ : A first-principles calculation. Chem. Phys. Lett. 2009, $478,175-179$.

(109) Long, R.; English, N. J. Synergistic Effects on Band GapNarrowing in Titania by Codoping from First-Principles Calculations. Chem. Mater. 2010, 22, 1616-1623.

(110) Kresse, G.; Hafner, J. Ab initiomolecular dynamics for liquid metals. Phys. Rev. B 1993, 47, 558-561.

(111) Kresse, G.; Furthmüller, J. Efficient iterative schemes forab initiototal-energy calculations using a plane-wave basis set. Phys. Rev. B 1996, 54, 11169-11186.

(112) Kresse, G.; Furthmüller, J. Efficiency of ab-initio total energy calculations for metals and semiconductors using a plane-wave basis set. Comput. Mater. Sci. 1996, 6, 15-50.

(113) Kresse, G.; Hafner, J. Ab initiomolecular-dynamics simulation of the liquid-metal-amorphous-semiconductor transition in germanium. Phys. Rev. B 1994, 49, 14251-14269.

(114) Krukau, A. V.; Vydrov, O. A.; Izmaylov, A. F.; Scuseria, G. E. Influence of the exchange screening parameter on the performance of screened hybrid functionals. J. Chem. Phys. 2006, 125, No. 224106.

(115) Heyd, J.; Scuseria, G. E.; Ernzerhof, M. Hybrid functionals based on a screened Coulomb potential. J. Chem. Phys. 2003, 118, 8207-8215. 
(116) Paier, J.; Marsman, M.; Hummer, K.; Kresse, G.; Gerber, I. C.; Ángyán, J. G. Screened hybrid density functionals applied to solids. J. Chem. Phys. 2006, 124, No. 154709.

(117) Regoutz, A.; Mascheck, M.; Wiell, T.; Eriksson, S. K.; Liljenberg, C.; Tetzner, K.; Williamson, B. A. D.; Scanlon, D. O.; Palmgren, P. A novel laboratory-based hard X-ray photoelectron spectroscopy system. Rev. Sci. Instrum. 2018, 89, No. 073105.

(118) Boonchun, A.; Reunchan, P.; Umezawa, N. Energetics of native defects in anatase $\mathrm{TiO}_{2}$ : a hybrid density functional study. Phys. Chem. Chem. Phys. 2016, 18, 30040-30046.

(119) Matsubara, M.; Saniz, R.; Partoens, B.; Lamoen, D. Doping anatase $\mathrm{TiO}_{2}$ with group V-b and VI-b transition metal atoms: a hybrid functional first-principles study. Phys. Chem. Chem. Phys. 2017, 19, 1945-1952.

(120) Huy, H. A.; Aradi, B.; Frauenheim, T.; Deák, P. Calculation of carrier-concentration-dependent effective mass in $\mathrm{Nb}$-doped anatase crystals of $\mathrm{TiO}_{2}$. Phys. Rev. B 2011, 83, No. 155201.

(121) Çelik, V.; Mete, E. Range-separated hybrid exchangecorrelation functional analyses of anatase $\mathrm{TiO}_{2}$ doped with $\mathrm{W}, \mathrm{N}, \mathrm{S}$, W/N, or W/S. Phys. Rev. B 2012, 86, No. 205112.

(122) Alotaibi, A. M.; Sathasivam, S.; Williamson, B. A. D.; Kafizas, A.; Sotelo-Vazquez, C.; Taylor, A.; Scanlon, D. O.; Parkin, I. P. Chemical Vapor Deposition of Photocatalytically Active Pure Brookite $\mathrm{TiO}_{2}$ Thin Films. Chem. Mater. 2018, 30, 1353-1361.

(123) Quesada-Gonzalez, M.; Williamson, B. A. D.; Sotelo-Vazquez, C.; Kafizas, A.; Boscher, N. D.; Quesada-Cabrera, R.; Scanlon, D. O.; Carmalt, C. J.; Parkin, I. P. Deeper Understanding of Interstitial Boron-Doped Anatase Thin Films as A Multifunctional Layer Through Theory and Experiment. J. Phys. Chem. C 2017, 122, 714-726.

(124) Mori-Sánchez, P.; Cohen, A. J.; Yang, W. Localization and Delocalization Errors in Density Functional Theory and Implications for Band-Gap Prediction. Phys. Rev. Lett. 2008, 100, No. 146401.

(125) Blöchl, P. E. Projector augmented-wave method. Phys. Rev. B 1994, 50, 17953-17979.

(126) Allison, T JANAF Thermochemical Tables. NIST Standard Reference Database 131996.

(127) Landmann, M.; Rauls, E.; Schmidt, W. G. The electronic structure and optical response of rutile, anatase and brookite $\mathrm{TiO}_{2}$. J. Phys.: Condens. Matter 2012, 24, No. 195503.

(128) Dou, M.; Persson, C. Comparative study of rutile and anatase $\mathrm{SnO}_{2}$ and $\mathrm{TiO}_{2}$ : Band-edge structures, dielectric functions, and polaron effects. J. Appl. Phys. 2013, 113, No. 083703.

(129) Patrick, C. E.; Giustino, F. GW Quasiparticle Bandgaps of Anatase $\mathrm{TiO}_{2}$ Starting from DFT+U. J. Phys.: Condens. Matter 2012, 24, No. 202201.

(130) Kang, W.; Hybertsen, M. S. Quasiparticle and optical properties of rutile and anatase $\mathrm{TiO}_{2}$. Phys. Rev. B 2010, 82, No. 085203.

(131) Gong, S.; Liu, B.-G. Electronic structures and optical properties of $\mathrm{TiO}_{2}$ : Improved density-functional-theory investigation. Chin. Phys. B 2012, 21, No. 057104.

(132) Chiodo, L.; Salazar, M.; Romero, A. H.; Laricchia, S.; Sala, F. D.; Rubio, A. Structure, electronic, and optical properties of $\mathrm{TiO}_{2}$ atomic clusters: An ab initio study. J. Chem. Phys. 2011, 135, No. 244704.

(133) Nieminen, R. M. Issues in first-principles calculations for defects in semiconductors and oxides. Modell. Simul. Mater. Sci. Eng. 2009, 17, No. 084001.

(134) Hine, N. D. M.; Frensch, K.; Foulkes, W. M. C.; Finnis, M. W. Supercell size scaling of density functional theory formation energies of charged defects. Phys. Rev. B 2009, 79, No. 024112.

(135) Murphy, S. T.; Hine, N. D. M. Anisotropic charge screening and supercell size convergence of defect formation energies. Phys. Rev. B 2013, 87, No. 094111.

(136) Lany, S.; Zunger, A. Assessment of correction methods for the band-gap problem and for finite-size effects in supercell defect calculations: Case studies for $\mathrm{ZnO}$ and GaAs. Phys. Rev. B 2008, 78, No. 235104
(137) Persson, C.; Zhao, Y.-J.; Lany, S.; Zunger, A. n-type doping ofCuInSe2andCuGaSe2. Phys. Rev. B 2005, 72, No. 054112.

(138) Ágoston, P.; Körber, C.; Klein, A.; Puska, M. J.; Nieminen, R. M.; Albe, K. Limits for n-type doping in $\mathrm{In} 2 \mathrm{O} 3$ and $\mathrm{SnO} 2$ : A theoretical approach by first-principles calculations using hybridfunctional methodology. J. Appl. Phys. 2010, 108, No. 053511.

(139) Stull, D. R.; Prophet, H. Ultrastructure Processing of Advanced Materials; NSRDS-NBS Publication No. 37; National Bureau of Standards: U.S. Washington, DC, 1971.

(140) Alkauskas, A.; McCluskey, M. D.; de Walle, C. G. V. Tutorial: Defects in semiconductors-Combining experiment and theory. J. Appl. Phys. 2016, 119, No. 181101.

(141) Taylor, F. H.; Buckeridge, J.; Catlow, C. R. A. Defects and Oxide Ion Migration in the Solid Oxide Fuel Cell Cathode Material LaFeO3. Chem. Mater. 2016, 28, 8210-8220.

(142) Buckeridge, J.; Jevdokimovs, D.; Catlow, C. R. A.; Sokol, A. A. Nonstoichiometry and Weyl fermionic behavior in TaAs. Phys. Rev. B 2016, 94, No. 180101.

(143) Janotti, A.; Varley, J. B.; Rinke, P.; Umezawa, N.; Kresse, G.; de Walle, C. G. V. Hybrid functional studies of the oxygen vacancy in $\mathrm{TiO}_{2}$. Phys. Rev. B 2010, 81, No. 085212.

(144) Morgan, B. J.; Watson, G. W. Intrinsic n-type Defect Formation in $\mathrm{TiO}_{2}$ : A Comparison of Rutile and Anatase from GGA $+U$ calculations. J. Phys. Chem. C 2010, 114, 2321-2328.

(145) Mattioli, G.; Alippi, P.; Filippone, F.; Caminiti, R.; Bonapasta, A. A. Deep versus Shallow Behavior of Intrinsic Defects in Rutile and Anatase $\mathrm{TiO}_{2}$ Polymorphs. J. Phys. Chem. C 2010, 114, 21694-21704.

(146) Deák, P.; Aradi, B.; Frauenheim, T. Polaronic effects in $\mathrm{TiO}_{2}$ calculated by the HSE06 hybrid functional: Dopant passivation by carrier self-trapping. Phys. Rev. B 2011, 83, No. 155207.

(147) Morgan, B. J.; Watson, G. W. Polaronic trapping of electrons and holes by native defects in anatase $\mathrm{TiO}_{2}$. Phys. Rev. B 2009, 80, No. 233102.

(148) Oba, F.; Nishitani, S. R.; Isotani, S.; Adachi, H.; Tanaka, I. Energetics of native defects in ZnO. J. Appl. Phys. 2001, 90, 824-828.

(149) Oba, F.; Togo, A.; Tanaka, I.; Paier, J.; Kresse, G. Defect energetics in $\mathrm{ZnO}$ : A hybrid Hartree-Fock density functional study. Phys. Rev. B 2008, 77, No. 245202.

(150) Janotti, A.; de Walle, C. G. V. Native point defects in $\mathrm{ZnO}$. Phys. Rev; B 2007, 76, No. 165202.

(151) Ágoston, P.; Albe, K.; Nieminen, R. M.; Puska, M. J. Intrinsicn-Type Behavior in Transparent Conducting Oxides: A Comparative Hybrid-Functional Study of $\mathrm{In}_{2} \mathrm{O}_{3}, \mathrm{SnO}_{2}$ and $\mathrm{ZnO}$. Phys. Rev. Lett. 2009, 103, No. 245501.

(152) Kilıç, Ç.; Zunger, A. Origins of Coexistence of Conductivity and Transparency in $\mathrm{SnO}_{2}$. Phys. Rev. Lett. 2002, 88, No. 095501.

(153) Singh, A. K.; Janotti, A.; Scheffler, M.; de Walle, C. G. V. Sources of Electrical Conductivity in $\mathrm{SnO}_{2}$. Phys. Rev. Lett. 2008, 101, No. 055502.

(154) Scanlon, D. O. Defect engineering of $\mathrm{BaSnO}_{3}$ for highperformance transparent conducting oxide applications. Phys. Rev. B 2013, 87, No. 161201.

(155) Sallis, S.; Scanlon, D. O.; Chae, S. C.; Quackenbush, N. F.; Fischer, D. A.; Woicik, J. C.; Guo, J.-H.; Cheong, S. W.; Piper, L. F. J. La-doped $\mathrm{BaSnO}_{3}$-Degenerate perovskite transparent conducting oxide: Evidence from synchrotron X-ray spectroscopy. Appl. Phys. Lett. 2013, 103, No. 042105.

(156) Wang, W.; Lu, C.; Ni, Y.; Su, M.; Huang, W.; Xu, Z. Preparation and characterization of visible-light-driven N-F-Ta tridoped $\mathrm{TiO}_{2}$ photocatalysts. Appl. Surf. Sci. 2012, 258, 8696-8703.

(157) Li, H.; Yin, S.; Wang, Y.; Sato, T. Efficient persistent photocatalytic decomposition of nitrogen monoxide over a fluorescence-assisted $\mathrm{CaAl}_{2} \mathrm{O}_{4}:(\mathrm{Eu}, \mathrm{Nd}) /(\mathrm{Ta}, \mathrm{N})$-codoped $\mathrm{TiO}_{2} /$ $\mathrm{Fe}_{2} \mathrm{O}_{3}$. Appl. Catal., B 2013, 132-133, 487-492.

(158) Furubayashi, Y.; Hitosugi, T.; Yamamoto, Y.; Inaba, K.; Kinoda, G.; Hirose, Y.; Shimada, T.; Hasegawa, T. A transparent metal: Nb-doped anatase $\mathrm{TiO}_{2}$. Appl. Phys. Lett. 2005, 86, No. 252101. 
(159) Konstantinova, E. A.; Kokorin, A. I.; Lips, K.; Sakthivel, S.; Kisch, H. EPR study of the illumination effect on properties of paramagnetic centers in nitrogen-doped $\mathrm{TiO}_{2}$ active in visible light photocatalysis. Appl. Magn. Res. 2009, 35, 421-427.

(160) Morgan, B. J.; Scanlon, D. O.; Watson, G. W. Small polarons in $\mathrm{Nb}$ - and $\mathrm{Ta}$-doped rutile and anatase $\mathrm{TiO}_{2}$. J. Mater. Chem. 2009, $19,5175-5178$.

(161) Osorio-Guillén, J.; Lany, S.; Zunger, A. Atomic Control of Conductivity Versus Ferromagnetism in Wide-Gap Oxides Via Selective Doping: V, Nb, Ta in Anatase TiO2. Phys. Rev. Lett. 2008, 100, No. 036601.

(162) Walsh, A.; Kehoe, A. B.; Temple, D. J.; Watson, G. W.; Scanlon, D. O. $\mathrm{PbO}_{2}$ : from semi-metal to transparent conducting oxide by defect chemistry control. Chem. Commun. 2013, 49, 448450.

(163) Catlow, C. R. A.; Sokol, A. A.; Walsh, A. Microscopic origins of electron and hole stability in $\mathrm{ZnO}$. Chem. Commun. 2011, 47, $3386-3388$.

(164) Scanlon, D. O.; Dunnill, C. W.; Buckeridge, J.; Shevlin, S. A.; Logsdail, A. J.; Woodley, S. M.; Catlow, C. R. A.; Powell, M. J.; Palgrave, R. G.; Parkin, I. P.; Watson, G. W.; Keal, T. W.; Sherwood, P.; Walsh, A.; Sokol, A. A. Band alignment of rutile and anatase $\mathrm{TiO}_{2}$. Nat. Mater. 2013, 12, 798-801.

(165) Swank, R. K. Surface Properties of II-VI Compounds. Phys. Rev. 1967, 153, 844-849.

(166) Butler, M. A. Prediction of Flatband Potentials at Semiconductor-Electrolyte Interfaces from Atomic Electronegativities. J. Electrochem. Soc. 1978, 125, 228-232.

(167) Gassenbauer, Y.; Klein, A. Electronic and Chemical Properties of Tin-Doped Indium Oxide (ITO) Surfaces and ITO/ZnPc Interfaces Studied In-situ by Photoelectron Spectroscopy. J. Phys. Chem. B 2006, 110, 4793-4801.

(168) Kramm, B.; Laufer, A.; Reppin, D.; Kronenberger, A.; Hering, P.; Polity, A.; Meyer, B. K. The band alignment of $\mathrm{Cu}_{2} \mathrm{O} / \mathrm{ZnO}$ and $\mathrm{Cu}_{2} \mathrm{O} / \mathrm{GaN}$ heterostructures. Appl. Phys. Lett. 2012, 100, No. 094102.

(169) Miao, M.-S.; Yarbro, S.; Barton, P. T.; Seshadri, R. Electron affinities and ionization energies of $\mathrm{Cu}$ and $\mathrm{Ag}$ delafossite compounds: A hybrid functional study. Phys. Rev. B 2014, 89, No. 045306.

(170) Quackenbush, N. F.; Allen, J. P.; Scanlon, D. O.; Sallis, S.; Hewlett, J. A.; Nandur, A. S.; Chen, B.; Smith, K. E.; Weiland, C.; Fischer, D. A.; Woicik, J. C.; White, B. E.; Watson, G. W.; Piper, L. F. $\mathrm{J}$. Origin of the Bipolar Doping Behavior of $\mathrm{SnO}$ from X-ray Spectroscopy and Density Functional Theory. Chem. Mater. 2013, 25, $3114-3123$

(171) Scanlon, D. O.; Watson, G. W. Uncovering the Complex Behavior of Hydrogen in Cu2O. Phys. Rev. Lett. 2011, 106, No. 186403.

(172) Scanlon, D. O.; Morgan, B. J.; Watson, G. W. Modeling the polaronic nature of p-type defects in $\mathrm{Cu}_{2} \mathrm{O}$ : The failure of GGA and GGA + U. J. Chem. Phys. 2009, 131, No. 124703.

(173) Scanlon, D. O.; Watson, G. W. Undoped n-Type $\mathrm{Cu}_{2} \mathrm{O}$ : Fact or Fiction? J. Phys. Chem. Lett. 2010, 1, 2582-2585.

(174) Scanlon, D. O.; Watson, G. W. Conductivity Limits in $\mathrm{CuAlO}_{2}$ from Screened-Hybrid Density Functional Theory. J. Phys. Chem. Lett. 2010, 1, 3195-3199.

(175) Allen, J. P.; Scanlon, D. O.; Piper, L. F. J.; Watson, G. W. Understanding the defect chemistry of tin monoxide. J. Mater. Chem. C 2013, 1, 8194-8208. 